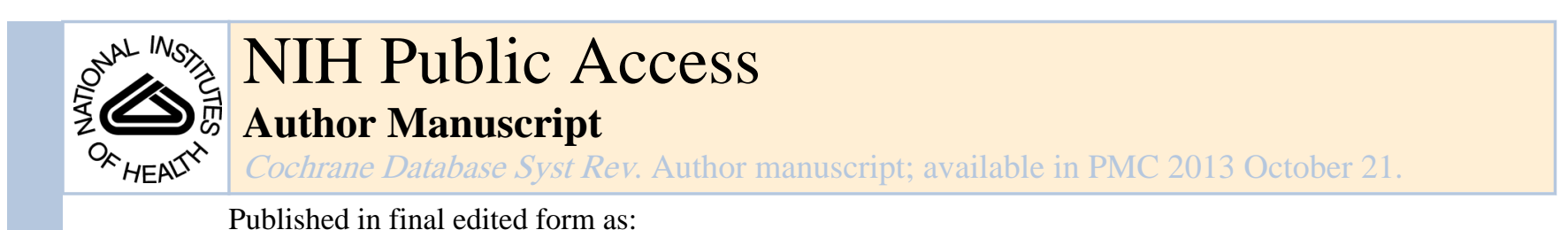

Published in final edited form as:

Cochrane Database Syst Rev. ; (4): CD006460. doi:10.1002/14651858.CD006460.pub2.

\title{
Conventional occlusion versus pharmacologic penalization for amblyopia
}

\author{
Tianjing Li ${ }^{1}$ and Kate Shotton ${ }^{2}$ \\ ${ }^{1}$ Cochrane Eyes and Vision Group US Project, Johns Hopkins Bloomberg School of Public \\ Health, Baltimore, USA \\ ${ }^{2}$ Department of Ophthalmology, Royal Victoria Infirmary, Newcastle upon Tyne, UK
}

\footnotetext{
Contact person Tianjing Li, Cochrane Eyes and Vision Group US Project, Johns Hopkins Bloomberg School of Public Health, 615 North Wolfe Street. E6006, Baltimore, MD 21205, USA, tli@jhsph.edu.

Contributions of authors

Conceiving the review: JC, TL

Designing the review: JC, TL, KS, AH, JF

Co-ordinating the review: TL, JC

Data collection for the review

- $\quad$ Designing electronic search strategies: CEVG Trials Search Co-ordinator

- Undertaking electronic searches: CEVG Trials Search Co-ordinator

- $\quad$ Screening search results: TL, KS, AH

- $\quad$ Organizing retrieval of papers: TL

- $\quad$ Screening retrieved papers against inclusion criteria: TL, KS, AH

- $\quad$ Appraising quality of papers: TJL, KS, AH

- $\quad$ Extracting data from papers: TJL, KS, AH

- Writing to authors of papers for additional information: TL

- $\quad$ Providing additional data about papers: TL, KS, AH

- $\quad$ Obtaining and screening data on unpublished studies: TL, KS
}

Data management for the review

- $\quad$ Entering data into RevMan: TL, KS

- $\quad$ Analysis of data: TL, KS

Interpretation of data

- $\quad$ Providing a methodological perspective: TL, KS

- $\quad$ Providing a clinical perspective: KS, JF

- $\quad$ Providing a policy perspective: KS, AH, JF

- $\quad$ Providing a consumer perspective: KS, AH

Writing the review: TL, KS

Providing general advice on the review: TL, KS, AH, JF

Securing funding for the review: TL

Performing previous work that was the foundation of the current study: TL, KS, AH, JF, JC

Declarations of interest

None known.

Differences between protocol and review

The new risk of bias table introduced by the Cochrane Collaboration was used to assess methodological quality of included studies. Post peer review for the manuscript, a decision was made to exclude systemic therapy and therefore the search strategies were amended accordingly and the review process started again with the new search results. 


\section{Abstract}

Background-Amblyopia is defined as defective visual acuity in one or both eyes without demonstrable abnormality of the visual pathway, and is not immediately resolved by wearing glasses.

Objectives-To assess the effectiveness and safety of conventional occlusion versus atropine penalization for amblyopia.

Search methods-We searched CENTRAL, MEDLINE, EMBASE, LILACS, the WHO International Clinical Trials Registry Platform, preference lists, science citation index and ongoing trials up to June 2009.

Selection criteria-We included randomized/quasi-randomized controlled trials comparing conventional occlusion to atropine penalization for amblyopia.

Data collection and analysis-Two authors independently screened abstracts and full text articles, abstracted data, and assessed the risk of bias.

Main results-Three trials with a total of 525 amblyopic eyes were included. One trial was assessed as having a low risk of bias among these three trials, and one was assessed as having a high risk of bias.

Evidence from three trials suggests atropine penalization is as effective as conventional occlusion. One trial found similar improvement in vision at six and 24 months. At six months, visual acuity in the amblyopic eye improved from baseline 3.16 lines in the occlusion and 2.84 lines in the atropine group (mean difference $0.034 \log$ MAR; $95 \%$ confidence interval (CI) 0.005 to 0.064 $\log$ MAR). At 24 months, additional improvement was seen in both groups; but there continued to be no meaningful difference (mean difference $0.01 \log$ MAR; $95 \%$ CI -0.02 to $0.04 \log$ MAR). The second trial reported atropine to be more effective than occlusion. At six months, visual acuity improved 1.8 lines in the patching group and 3.4 lines in the atropine penalization group, and was in favor of atropine (mean difference $-0.16 \log$ MAR; $95 \%$ CI -0.23 to $-0.09 \log$ MAR). Different occlusion modalities were used in these two trials. The third trial had inherent methodological flaws and limited inference could be drawn.

No difference in ocular alignment, stereo acuity and sound eye visual acuity between occlusion and atropine penalization was found. Although both treatments were well tolerated, compliance was better in atropine. Atropine penalization costs less than conventional occlusion. The results indicate that atropine penalization is as effective as conventional occlusion.

Authors' conclusions-Both conventional occlusion and atropine penalization produce visual acuity improvement in the amblyopic eye. Atropine penalization appears to be as effective as conventional occlusion, although the magnitude of improvement differed among the three trials. Atropine penalization can be used as first line treatment for amblyopia.

\section{Plain language summary}

\section{Treatment of amblyopia (lazy eye) with patching or drops/drug treatment}

Amblyopia (referred to as lazy eye) is a common childhood condition, and is defined as defective visual acuity in one or both eyes, which is present with no demonstrable abnormality of the visual pathway and is not immediately resolved by wearing glasses. Treatment for amblyopia usually starts with prescribing necessary glasses to correct visually important refractive errors followed by promoting the use of the amblyopic eye. This systematic review aimed to synthesize the best available evidence regarding the effectiveness and safety of two different treatment options used to promote the use of the amblyopic eye: conventional occlusion (patching) and atropine penalization (drops). Conventional occlusion involves patching the non-amblyopic eye with an opaque patch for a 
set number of hours per day. Atropine penalization involves the instillation of atropine sulphate to blur the eyesight of the better-seeing eye.

We included three randomized or quasi-randomized controlled trials with a total of 525 amblyopic eyes. Evidence from three trials (one of good methodological quality) suggests both conventional occlusion and atropine penalization produce visual acuity improvement in the short-term (six months) and long-term ( 24 months) in the amblyopic eye after initiation of therapy. The results of this review show atropine penalization to be as effective as conventional occlusion, although the amount of improvement achieved differed among the three trials. Although both treatments were well tolerated, compliance was better with atropine penalization. Atropine penalization can be used as first line treatment for amblyopia.

\section{Background}

\section{Description of the condition}

Amblyopia (referred to as lazy eye) is a common childhood condition, and is defined as defective visual acuity in one or both eyes, which is present with no demonstrable abnormality of the visual pathway and is not immediately resolved by wearing glasses. The term is used most frequently to refer to the unilateral condition, although it may be unilateral or bilateral. In adults, it is usually diagnosed by a significant reduction in visual acuity, which cannot be improved by refractive correction, and which has no obvious organic cause (AAO 2007; Ciuffreda 1991; Levi 2006). Factors commonly associated with amblyopia and sometimes used for classification include strabismus (squint), stimulus deprivation such as cataract or ptosis, and those caused by anisometropia or unequal refractive error (need for glasses) between the two eyes.

Amblyopia develops during early childhood (infancy to 12 years or older) when the visual system is vulnerable to changes in visual stimulation (Ansons 2001). During this time it is usually a reversible condition. If left untreated it will remain as a permanent visual defect into adulthood (Rahi 2002; Tommila 1981). About $25 \%$ of patients with amblyopia will have a visual acuity in the amblyopic eye worse than 20/100 (Woodruff 1994).

Epidemiology-Amblyopia potentially places a substantial burden on patient and health care resources as the visual impairment can last a lifetime. The estimated prevalence of amblyopia is between $2 \%$ to $3 \%$, depending on diagnostic criteria used and the population selected (AAO 2007; Attebo 1998; Brown 2000; Flom 1985; Williams 2002). Two recent Australian adult population-based cohort studies, Visual Impairment Project and Blue Mountains Eye Study, reported the prevalence of unilateral amblyopia to be $3.1 \%$ and $3.2 \%$, respectively, when amblyopia was defined as visual acuity of 6/9 or worse (Attebo 1998; Brown 2000). Lower amblyopia prevalence was reported in preschool screening programs (Williams 2002).

Risk factors associated with the development of amblyopia include premature birth, low birth weight, retinopathy of prematurity, cerebral palsy, mental retardation, family history of amblyopia, congenital cataract, maternal factors such as smoking, antihistamine ingestion and alcohol (AAO 2007; AOA 1997). However, many children who present with amblyopia have none of these risk factors.

Presentation and diagnosis-Amblyopia of certain etiologies may not produce symptoms that are obvious to a parent or the affected child. 
Unilateral refractive amblyopia may go unnoticed for years because the child typically has good visual acuity in the normal eye. As a result, many children remain undiagnosed, especially before they begin school. The refractive error is detected at the first appointment but a diagnosis of amblyopia cannot be made until the child has been reassessed with the refractive correction in place. Bilateral refractive amblyopia can be easier to detect as the child may struggle with close work or complain of reduced or blurred vision.

In strabismic amblyopia, strabismus is present and the eyes are not aligned properly resulting in one eye being used less than the other. The majority of children with strabismic amblyopia can be detected by the appearance of the strabismus (squint) (AAO 2007). However, the degree of strabismus may range from a very small deviation, for example, microtropia (five degrees or less) with useful binocular vision, to a very large deviation, which may affect a person's appearance.

Deprivation amblyopia caused by cataracts may be detected at discharge from hospital of new borns or at eight-week postnatal examination. Cosmetically unacceptable ptosis (droopy lid) will present at an early age for treatment.

The basis of a diagnosis of amblyopia is defective central visual processing, therefore, careful assessment of the retina, optic nerve and all other structures within the eye is essential. Attention should also be paid to the potential risk factors for amblyopia, such as a positive family history for strabismus, amblyopia, or media opacity (AAO 2007). The diagnosis is established by a unilateral or bilateral reduction of best-corrected visual acuity not attributable to structural abnormalities of the visual pathways.

Criteria for a diagnosis of unilateral amblyopia (AAO 2007) include:

1. Unequal fixation behavior.

2. 2-octave difference in preferential looking, or $\geq 2$ line interocular difference in best corrected visual acuity.

\section{Description of the intervention}

The aim of all treatment options for amblyopia is to obtain the best possible visual acuity in the amblyopic eye. The initial treatment for any patient with amblyopia is full-time wear of necessary refractive correction. The period of refractive adaptation (time taken to settle into glasses) is thought to be up to 24 weeks (Moseley 2002). The effectiveness of refractive correction as an initial treatment for amblyopia has been summarized in a recent Cochrane systematic review (Shotton 2008b). The initial treatment is usually followed by promoting the use of the amblyopic eye through limiting the use of the sound eye, such as conventional occlusion or atropine penalization. Three published Cochrane systematic reviews (AntonioSantos 2006; Shotton 2008a; Shotton 2008b) examine various interventions for patients with different types of amblyopia. None have assessed specifically the comparison between occlusion therapy and atropine penalization. Therefore, the treatment options to be discussed within this review are occlusion therapy and atropine penalization.

\section{How the intervention might work}

1. Occlusion treatment-Occlusion treatment for amblyopia was first described in 1772 (Fells 1990). Patching the non-amblyopic eye with an opaque patch forces the patient to use the amblyopic eye. Opinions vary on the number of hours of patching per day that should be prescribed, ranging from one hour to full-time (PEDIG 2002), and the concurrent activities whilst patching is being carried out (PEDIG 2006). 
2. Atropine penalization-Atropine penalization has been an alternative to occlusion therapy for amblyopia for over a century. Atropine sulphate, a long acting topical cycloplegic agent, is instillated into the sound eye (Foley-Nolan 1997; PEDIG 2002; Swann 1974) to blur the vision in the sound eye for near activities, hence forcing the amblyopic eye to be used preferentially for near vision tasks. Atropine penalization can be used alone or in combination with optical penalization. Opinions vary on the number of days that atropine penalization should be prescribed (PEDIG 2004).

Factors affecting outcome: Compliance plays a large role in determining the effectiveness of occlusion therapy (Newsham 2000; Simons 1999; Simons 2005). Prescribed doses of treatment may be less than the actual dose taken by patients. Less treatment may be better tolerated and as effective as more traditionally used dosage (Wu 2006). In addition, the initial visual acuity, type of amblyopia, treatment initiation age, and the efficacy of treatment modality may also play a role.

\section{Why it is important to do this review}

Occlusion therapy with patching of the sound eye has been the mainstay of amblyopia treatment. The success of occlusion depends heavily on compliance. Success rates vary from $30 \%$ to 95\% (Kaye 2002; Repka 1993). There are also conceptual concerns about the degree to which unilateral occlusion disrupts binocularity, as well as the number of hours of patching per day that should be prescribed.

The practical benefit of atropine penalization is its ease of administration, reliable assessment of compliance, and its low cost. It is thought to be more acceptable than occlusion to both children and their parents, because it avoids both the skin irritation and social stigma of a patch (Simons 1997). The reported compliance rates vary from $78 \%$ to $100 \%$ for atropine penalization (Kaye 2002). The disadvantage of atropine penalization is its potential toxicity and its duration of effect if reverse amblyopia is detected.

Reverse amblyopia, in which the initially better eye is made amblyopic as a result of the treatment, seems particularly likely to arise when patients fail to continue follow-up visits to the treating physician (Simons 1997). This can occur with both treatment options.

A systematic review is needed to examine the evidence with regard to effectiveness and safety of occlusion therapy compared to atropine penalization in treating amblyopia.

\section{Objectives}

This systematic review aimed to synthesize the best available evidence regarding the effectiveness and safety of conventional occlusion therapy compared to atropine penalization in treating amblyopia.

\section{Methods}

\section{Criteria for considering studies for this review}

Types of studies-We included only randomized controlled trials (RCTs) and quasirandomized controlled trials (CCTs) in this review. Studies that had not used randomization to allocate participants to treatment groups but had used techniques intended to allocate patients in an unbiased fashion were considered to be quasi-randomized trials. Some examples include allocation based on day of the week, year of birth, or hospital admission number of consecutive patients. There was no date or language restriction placed on studies selected for this review. 
Types of participants-We included trials that enrolled participants of any age with either unilateral strabismic, anisometropic, or mixed (strabismic-refractive) amblyopia. Depriviation amblyopia was not included since treatment for this type of amblyopia has been covered in another Cochrane systematic review (Antonio-Santos 2006). There was no restriction on sex or severity of the amblyopia placed on participants of studies selected for this review.

Types of interventions-We originally planned to include trials that compared conventional occlusion with any pharmacologic therapy, including systemic therapy such as levodopa and carbidopa. Given the comments from the peer reviewers and editors, as well as the fact that other pharmacological treatments are not penalization of the better eye, we decided post hoc to limit this review to trials that compared conventional occlusion (patching) of any type (part-time or full-time, total adhesive, partial occlusion, shield, and pirate patch) to atropine penalization, with or without conventional occlusion. Systemic pharmacologic treatment for amblyopia will be covered in a separate systematic review.

\section{Types of outcome measures}

Primary outcomes: The primary outcome for this review was visual acuity of the amblyopic eye on an age specific test at 12 months from commencement of treatment analyzed in continuous $\log$ MAR units. The long-term stability of treatment effects is of particular importance to children and parents. For this reason, we chose outcome measured after 12 months of treatment as the primary outcome of interest. The primary outcome was also analyzed as dichotomous and categorical data if they were reported in the trials. The prespecified categories were as follow:

\section{Best-corrected visual acuity dichotomized into:}

- normal: $0.2 \log$ MAR (6/9 or 20/30 Snellen equivalent) or better;

- residual deficit: worse than $0.2 \operatorname{LogMAR}$.

\section{Change in visual acuity categorized by:}

- 2 or more lines improvement from baseline;

- $\quad$ no change (within 2 lines from baseline);

- 2 or more lines loss.

We pre-specified that we would analyze visual acuity at other follow-up times if they were reported in the trials.

Secondary outcomes: The secondary outcome for this review was change in binocular function measured by change in stereo acuity according to the stereopsis test applied in each trial. We examined the secondary outcome at different follow-up times as reported in the included trials.

Harms: We tabulated all systemic and ocular adverse effects related to either conventional occlusion or pharmacologic penalization reported in the included studies. Specific adverse effects of interest were:

Mild

1. reduction in visual acuity of the non-amblyopic eye not requiring treatment;

2. allergy to treatment such as skin irritation for patching treatment;

3. mild allergic reaction to pharmacological treatment not requiring treatment. 
Severe

1. reduction in visual acuity of the non-amblyopic eye requiring further treatment;

2. severe allergy to patches or pharmacological treatment requiring further treatment;

3. intractable diplopia (double vision) if suppression area eliminated due to occlusion;

4. psychological distress.

Economic data: We documented the cost of treating amblyopia.

Quality of life data: We reported any quality of life measures associated with having residual amblyopia and treated amblyopia.

\section{Search methods for identification of studies}

Electronic searches-We searched the Cochrane Central Register of Controlled Trials (CENTRAL) (which contains the Cochrane Eyes and Vision Group Trials Register) (The Cochrane Library, Issue 2, 2009), MEDLINE (January 1950 to June 2009), EMBASE (January 1980 to June 2009), Latin American and Caribbean Literature on Health Sciences (LILACS) (January 1982 to June 2009) and the WHO International Clinical Trials Registry Platform (WHO ICTRP). There were no language or date restrictions in the search for trials. The electronic databases were last searched on 26 June 2009.

Post peer review, we decided to investigate systemic pharmacologic therapy for amblyopia in a separate systematic review. For this reason, we modified the electronic searches in June 2009. Relevant trials identified in this search are listed as "Studies awaiting classification", and will be included as an update of the current review in Issue 1, 2010 of The Cochrane Library.

See: Appendices for details of search strategies for CENTRAL (Appendix 1), MEDLINE (Appendix 2), EMBASE (Appendix 3), LILACS (Appendix 4) and WHO ICTRP (Appendix $5)$.

Searching other resources-We manually searched the reference lists of the reports of trials included in the review for additional trials. We used the Science Citation Index to find studies that had cited the included trials. We searched the Pediatric Eye Disease Investigator Group (PEDIG) web site (http://public.pedig.jaeb.org) for ongoing trials and protocols of included trials. We did not handsearch journals and conference proceedings to find additional trials.

\section{Data collection and analysis}

Selection of studies-At least two authors independently assessed the titles and abstracts resulting from the searches against the eligibility criteria. Each abstract was labeled as 'include', 'unclear' or 'exclude'. We obtained full text copies of all articles for abstracts labeled 'include' or 'unclear'. Each full text article was examined by two authors independently to determine final eligibility of this trial. We resolved discrepancies between the authors through discussion. We documented the excluded studies and reasons for exclusion. For included studies, we obtained all articles pertinent to this trial, abstracted data and assessed risk of bias. 
Data extraction and management-Two authors independently abstracted data from included studies onto paper data collection forms developed and pilot-tested specifically for this review. We decided as a priority to extract the following details.

1. Methods: we extracted data on the method of allocation, masking of outcome assessment, exclusions after randomization, losses to follow-up, compliance, and other aspects of study design and conduct.

2. Participants: we extracted data on the country where participants were enrolled, age, sex, number randomized, main inclusion and exclusion criteria.

3. Interventions: we described the conventional occlusion method and atropine penalization method implemented.

4. Outcomes: we extracted data on primary and secondary outcomes over different follow-up periods.

5. Adverse events: we documented mild and severe adverse events.

6. Quality of life issues: we planned to extract data on the impact of living with untreated amblyopia, the impact on family life of the treatment process and any information regarding the perceived stigma associated with treatment.

7. Economic data: we reported the cost of treating amblyopia.

8. Notes: we reported funding sources relevant to each trial.

We resolved discrepancies by discussion. One review author (TL) entered all data into Review Manager (RevMan 5) and this was verified by a second author (KS).

Assessment of risk of bias in included studies-Two authors, working independently, assessed the risk of bias for each trial using the validated methods described in Chapter 8 of the Cochrane Handbook for Systematic Reviews of Interventions (Higgins 2008). The following six quality parameters were considered in assessing the risk of bias: 1) sequence generation; 2) allocation concealment; 3 ) masking (blinding) of outcome assessors; 4) incomplete outcome data; 5) selective outcome reporting; 6) other sources of bias. Each of the parameters was assessed as: 'Yes', low risk of bias, 'No', high risk of bias, and 'Unclear', unclear risk of bias.

Measures of treatment effect-We followed the guidelines in Section 9 of the Cochrane Handbook for Systematic Reviews of Interventions (Deeks 2008) for data analyses. We calculated the weighted mean difference for continuous outcomes (e.g., visual acuity, change in stereo acuity). We used risk ratios as effect measurement for dichotomous outcomes (e.g., visual acuity dichotomized into normal or residual deficit).

Unit of analysis issues-Of the three included studies, only one eye from each participant was randomized. The unit of randomization and analysis for efficacy outcome was the individual eye. If cluster-randomized trials and cross-over trials are included in the updates of this review, we will extract data from an analysis that properly accounts for the non-independence within the cluster. If the cluster-randomized trials and cross-over trials have in the past failed to report appropriate analyses, we will perform the analyses following the guidelines in section 9.3 of the Cochrane Handbook for Systematic Reviews of Interventions (Deeks 2008).

Dealing with missing data-We contacted and received responses from the lead investigator for one of the included trials that had missing information (Tejedor 2008). 
Assessment of heterogeneity-We assessed clinical heterogeneity by examining the characteristics of each study qualitatively. We planned to use forest plots of results of the studies, the results of the $\mathrm{Chi}^{2}$ test for statistical heterogeneity and the value of the $\mathrm{I}^{2}$ to estimate the amount of statistical heterogeneity between trials if a meta-analysis were carried out.

Assessment of reporting biases-We planned to use a funnel plot to assess publication bias when a sufficient number of trials were identified.

Data synthesis-We prespecified that if substantial clinical or statistical heterogeneity were present, we would not combine study results but would present an estimate of effect and associated confidence interval for each individual trial. If there was little variation between trials $\left(\mathrm{I}^{2}\right.$ low), we would combine the results in a meta-analysis using both the fixed-effect and random-effects models.

Subgroup analysis and investigation of heterogeneity-We planned to conduct subgroup analyses by the type of amblyopia (strabismic, anisometropic and mixed amblyopia) and type of occlusion (part-time and full-time occlusion) when sufficient data were available in the included studies.

Sensitivity analysis-We planned to conduct sensitivity analyses to determine the impact of exclusion of studies with lower methodological quality and industry funded studies.

\section{Results}

\section{Description of studies}

Results of the search-The electronic searches retrieved 106 records (26 from CENTRAL, 41 from MEDLINE and 39 from EMBASE). After removing the duplicates, 56 titles and abstracts underwent initial screening for eligibility, and 17 appeared to be relevant. One abstract (Yan 2008) is awaiting classification as the corresponding full text article is not available. Of the 16 articles that underwent review of the full text, four reports were excluded: three were not reports of RCTs or CCTs, and one did not address the comparisons of interest.

The remaining 12 articles reporting findings from two trials were relevant to this review (Foley-Nolan 1997; PEDIG 2002). We identified one additional trial by searching the Science Citation Index (Tejedor 2008). No additional trial was identified by searching the reference lists of the included studies or WHO ICTRP. Altogether, three trials were included in this review.

As described previously, the amendment to the electronic searches was a post hoc decision. By the time the search was completed, we identified three additional articles that were relevant to the review. One described follow-up at age 10 of the included PEDIG 2002 trial. The other two articles, reporting findings of two trials that compared patching versus atropine penalization for the treatment of amblyopia in older children (aged seven to 12 years, and eight to 20 years respectively) (Menon 2008; PEDIG 2008), are listed under "Characteristics of studies awaiting classification". Results from these three reports will be included as an update of the current review in Issue 1, 2010 of The Cochrane Library.

Included studies-We have presented the clinical characteristics for each included study in the "Characteristics of included studies" table. 
Types of participants: We included three trials (Foley-Nolan 1997; PEDIG 2002; Tejedor 2008) from three countries (Ireland, United States and Spain) with a total of 525 amblyopic eyes in the review. The trials varied in size with the smallest enrolling 36 participants (Foley-Nolan 1997) to the largest enrolling 419 participants (PEDIG 2002). Included participants were boys and girls aged from two to 10 years with all levels and types of amblyopia (strabismus, anisometropia, or both).

We found clinical heterogeneity in several aspects, including the age of participants, baseline visual acuity and type of amblyopia. Different distribution of these factors across trials were of concern because older age at commencement of treatment, worse starting visual acuity, and strabismus as the cause of amblyopia have been related to poorer response to amblyopia treatment (Flynn 1998; Hiscox 1992; Newman 1996; Woodruff 1994).

Specifically, Foley-Nolan 1997 enrolled 36 Irish children younger than nine years of age with all levels and types of amblyopia. No participant had received previous treatment prior to their inclusion. Tejedor 2008 enrolled 70 Spainish children between two to 10 years of age. No participant had received previous treatment of amblyopia prior to inclusion. Visual acuity in the amblyopic eye was at least $0.5 \log$ MAR (mean $=0.43 \log \mathrm{MAR}$ ). The inclusion criteria only allowed for moderate to mild amblyopia. PEDIG 2002 enrolled 419 U.S. children younger than seven years of age with all types of amblyopia. Baseline vision in the amblyopic eye ranged from 0.3 to $0.7 \log$ MAR (20/40 to 20/100 Snellen equivalent). Children in whom any ocular pathology was present or who had received more than two months of amblyopia therapy in the past two years were excluded. Foley-Nolan 1997 included amblyopic eyes of worse baseline visual acuity and a larger proportion of children with strabismic amblyopia compared with the other two trials.

Types of interventions: The included trials evaluated a variety of interventions and prescribing regimens. Different regimens of occlusion, including partial occlusion and total occlusion, and atropine penalization were studied. Specifically, Foley-Nolan 1997 prescribed full-time total occlusion for one week per year of life. Once vision improved to $6 / 9$ or better, occlusion was reduced to half days. The average duration of full-time total occlusion was 4.3 months (range two to nine months) but compliance was documented to be only 55\%. PEDIG 2002 prescribed a minimum of six hours daily occlusion with some participants (20\%) prescribed 12 hours daily over the initial six month period. After six months, atropine or patching was followed by best clinical care for two years. The variable nature of the occlusion regimens for the participants makes it difficult to report exactly how much occlusion was worn by the participants. Excellent compliance was documented in $49 \%$ of cases. Tejedor 2008 used partial occlusion by means of positive defocus of the sound eye. The treatment period was six months.

The comparison intervention of these three trials, atropine penalization, was prescribed more consistently than that of occlusion regimen. Foley-Nolan 1997 and PEDIG 2002 prescribed one drop per day of atropine sulphate 1\%; Tejedor 2008 prescribed $1 \%$ atropine twice weekly when interocular acuity difference was present, and once weekly for maintenance therapy. A recent trial (PEDIG 2004) has shown that weekend atropine provides a similar improvement in vision to daily atropine for participants aged between three to seven years with moderate amblyopia ( 0.3 to $0.6 \log \mathrm{MAR}, 20 / 40$ to $20 / 80$ Snellen equivalent).

Types of outcomes: All trials examined visual acuity in the amblyopic eye and the sound eye. However, the vision test used varied: PEDIG 2002 used the validated Amblyopia Treatment Study visual acuity testing protocol; Tejedor 2008 used the logMAR Crowded Glasgow acuity cards; and Foley-Nolan 1997 used the Snellen chart, Kay's Pictures, or Sheridan-Gardener test types, depending on the age and comprehension of the patient. 
Different measurement instruments may introduce information bias and heterogeneity in determining visual acuity outcomes. Certain vision tests are known to be comparable, crowded Kay's Pictures and Crowded LogMAR, although crowded Kay's Pictures is an easier test to perform (Jones 2003)

The timescale at which visual acuity was recorded during the trial also varied considerably. PEDIG 2002 assessed visual acuity at baseline, six and 24 months follow-up. Foley-Nolan 1997 at baseline, the conclusion of therapy (treatment was considered to have been concluded when a visual acuity of $6 / 6$ was achieved, or when visual acuity remained static over three successive assessments), and after the longest term follow-up. Tejedor 2008 scheduled follow-up appointments every two to six months, depending on the severity of amblyopia and the response to treatment; however, for statistical analysis data were recorded at three and six month follow-up examinations. Different follow-up schedules may introduce heterogeneity that affects the outcome as the effects of treatment may vary with time.

PEDIG 2002 examined ocular alignment and stereo acuity at two-year follow-up. Safety and compliance of treatments were reported.

Excluded studies-Of those articles that underwent review of the full text, four reports were excluded (Chatzistefanou 2000; Cole 2001; Sheiman 2005; Wu 2006): three were not reports of RCTs or CCTs, and the remaining report did not address the comparisons of interest. We have presented the clinical characteristics for each excluded study in the 'Characteristics of excluded studies' table.

\section{Risk of bias in included studies}

We evaluated the risk of bias for each trial using six pre-specified criteria. PEDIG 2002 was judged to have the lowest risk of bias among these three trials. Foley-Nolan 1997 was assessed as having a high risk of bias. We also interpreted the possible effect of methodological differences among studies, investigated the strength and weakness of the evidence, and determined whether studies should be combined in a meta-analysis (see Figure 1 'Methodological quality summary').

Sequence generation-The randomization sequence was inadequately generated in Foley-Nolan 1997. Participants were assigned to treatment groups on an alternate basis. Because patient assignment involved such a systematic or non-random approach, confounding may be introduced. PEDIG 2002 and Tejedor 2008 used computer-generated random numbers, which was deemed as an appropriate sequence generation process.

Allocation-Adequate allocation concealment prevents selection bias. We considered investigators enrolling participants possibly could foresee assignment in Foley-Nolan 1997, and thus may have introduced selection bias. Randomization in PEDIG 2002 was accomplished on the study's web site, which was one form of central allocation with adequate concealment. Tejedor 2008 did not report explicitly in the article how allocation was concealed. Through written personal communication, the lead investigator informed us that a central office steering committee handled the randomization process so that investigators who determined eligibility and enrolled individuals were unaware of the assignment order.

Masking (blinding) of primary outcome assessment-The primary outcome for this review was visual acuity in the amblyopic eye. All three trials masked personnel examined visual acuity. Specifically, PEDIG 2002 reported that the vision tester was masked to treatment group for $97 \%$ of the examinations at six months, and $92 \%$ at 24 
months. The reported success of masking in Tejedor 2008 was $90.6 \%$ (29/32) of the optical and $87 \%(27 / 31)$ of the pharmacologic penalization groups.

Incomplete outcome data-Tejedor 2008 excluded seven (10\%) participants from the analyses. Excluding randomized participants from analyses was of particular concern because those excluded may have a different distribution of baseline characteristics and different responses to treatment from those retained, and therefore may introduce bias. Posttreatment visual acuity was reported for all 36 participants in Foley-Nolan 1997. However, there was limited information on the duration of follow-up, in particular the time point at which the post-treatment visual acuity was assessed. If visual acuity were measure at different follow-up times, information bias would have been introduced. PEDIG 2002 had $96 \%$ and $95 \%$ follow-up rate at six-months and two-years respectively. All analyses followed the intention-to-treat principle. Missing values were handled using last follow-up carry forward method.

Selective reporting-We had insufficient information to assess the risk of selective reporting bias in Foley-Nolan 1997 and Tejedor 2008. All outcomes listed in the PEDIG baseline paper and protocol were reported in the subsequent publications (PEDIG 2002).

Other potential sources of bias-The statistical analyses for two trials were inadequate (Foley-Nolan 1997; Tejedor 2008). The analyses compared pre and post-treatment visual acuity in each treatment group. However, no between group comparison was made and therefore no meaningful inference could be drawn. Tejedor 2008 provided standard deviations for the visual acuity improvement in each arm. We used this information to calculate the between group effect estimate. However, this estimate should be interpreted cautiously since missing values have not been accounted for. Lastly, the sample size was very small to detect any meaningful clinical difference in Foley-Nolan 1997.

We did not assess the potential for publication bias using a funnel plot because only three trials were included.

The risk of bias assessment has alerted us to one study with methodological concern (FoleyNolan 1997). The study characteristics, including study methods, population and intervention varied across all three trials. As a result of substantial clinical heterogeneity, we decided not to pool the quantitative data in a meta-analysis. Instead, we reported the results separately for each trial wherever data were available.

\section{Effects of interventions}

Primary outcomes-Of the three trials included in the review, data were available for the comparison between conventional occlusion versus atropine penalization with or without optical penalization.

PEDIG 2002: In this trial, 419 participants were randomized to receive either conventional occlusion (215 participants) or atropine sulphate penalization (204 participants). The primary outcome of the trial was visual acuity in the amblyopic eye after six months of treatment.

At six months, visual acuity in the amblyopic eye improved substantially from baseline in both the patching and atropine group (3.16 lines and 2.84 lines respectively). Improvement was initially faster in the patching group, but at six months, the difference in visual acuity between the two treatment groups was small and clinically inconsequential (mean difference (MD) $0.034 \log \mathrm{MAR}$; 95\% confidence interval (CI) 0.005 to $0.064 \log \mathrm{MAR}$ ) (Analysis 1.1). 
The six-month visual acuity was $0.2 \log$ MAR (6/9 or 20/30 Snellen equivalent) or better in the amblyopic eye in $63.5 \%(132 / 208)$ of the patching group and $53.1 \%(103 / 194)$ of the atropine group (risk ratio (RR) 1.20; 95\% CI 1.01 to 1.41) (Analysis 1.2). Among participants who had both baseline and six-month visual acuity measurement, $87.0 \%$ $(181 / 208)$ of the patching group and $82.5 \%(160 / 194)$ of the atropine group gained 2 or more lines of vision in the amblyopic eye from baseline (RR 1.06; 95\% CI 0.97 to 1.15 ) (Analysis 1.3); 13.0\% (27/208) of the patching group and 17.5\% (34/194) of the atropine group had visual acuity within 2 lines of baseline (RR $0.74 ; 95 \%$ CI 0.46 to 1.18) (Analysis 1.4); no participant experienced a loss of 2 or more lines of vision in either the patching or atropine group.

Most patients were prescribed amblyopia therapy beyond six months until the two-year outcome: $91 \%$ in the patching group and $85 \%$ in the atropine group. The actual treatment regimens prescribed were associated with the initial treatment assignment at randomization. Patching was prescribed for $84 \%$ of children treated with patching during the initial six months, and atropine was prescribed for $78 \%$ of children treated with atropine during the initial six months.

At 24 months, additional visual acuity improvement in the amblyopic eye was seen in both treatment groups. Visual acuity improved from baseline to a mean of 3.7 lines in the patching group and 3.6 lines in the atropine group. There continued to be no meaningful difference between groups in mean visual acuity score (MD $0.01 \operatorname{logMAR} ; 95 \%$ CI -0.02 to $0.04 \log$ MAR) (Analysis 1.1). The 24-month acuity was $0.2 \log$ MAR (6/9 or 20/30 Snellen equivalent) or better in the amblyopic eye in $75.0 \%(141 / 188)$ of the patching group and $70.9 \%$ (124/175) of the atropine group (RR 1.06; 95\% CI 0.93 to 1.20 ) (Analysis 1.2). Among participants who had both baseline and 24-month visual acuity measurement, 90.4\% $(170 / 188)$ of the patching group and 86.9\% (152/175) of the atropine group gained 2 or more lines of vision in the amblyopic eye from baseline (RR 1.04; 95\% CI 0.97 to 1.12 ) (Analysis 1.3); 9.6\% (18/188) of the patching group and 12.6\% (22/175) of the atropine group had visual acuity within 2 lines of baseline (RR 0.76; 95\% CI 0.42 to 1.37) (Analysis 1.4); one participant in the atropine group experienced a loss of 2 or more lines of vision in the amblyopic eye.

Tejedor 2008: Seventy participants were randomized to receive either optical penalization achieved by positive defocus of the sound eye ( 35 participants) or atropine $1 \%$ prescribed twice weekly (35 participants). The primary outcome of the trial was visual acuity of the amblyopic eye. The duration of treatment was six months and outcomes were assessed at the conclusion of treatment.

At six months, improvement in visual acuity from baseline occurred in both the optical penalization and atropine group. The trial authors did not report the effect estimates (e.g. mean difference, risk ratio) between groups. We calculated the effect estimates and CIs based on available information. Visual acuity in the amblyopic eye improved by 1.8 lines in the optical penalization group and 3.4 lines in the atropine penalization group (MD -0.16 $\log$ MAR; $95 \%$ CI -0.23 to $-0.09 \log$ MAR) (Analysis 1.1). Improvement in vision was greater in the atropine group than the optical penalization group. Visual acuity was 0.2 LogMAR or better (6/9 or 20/30 Snellen equivalent) in the amblyopic eye in 56.3\% (18/32) of the optical penalization group and 74.2\% (23/31) of the atropine group (RR 0.76; 95\% CI 0.52 to 1.10) (Analysis 1.2). At six months, 56.3\% (18/32) of children treated with optical penalization and $87.1 \%$ (27/31) of those treated with atropine gained 2 or more lines of vision in the amblyopic eye from baseline (RR 0.65; 95\% CI 0.46 to 0.90 ) (Analysis 1.3); $43.8 \%(14 / 32)$ of the patching group and $12.9 \%$ (4/31) of the atropine group had visual 
acuity within 2 lines of baseline (RR 3.39; 95\% CI 1.25 to 9.17) (Analysis 1.4); no participant experienced a loss of visual acuity in the amblyopic eye.

Foley-Nolan 1997: Thirty-six participants were randomized to receive either full-time occlusion for one week per year of life (18 participants) or $1 \%$ atropine sulphate drops instilled daily (18 participants). The primary outcome for the trial was change in acuity of the amblyopic eye at the end of treatment. The treatment interval ranged from two to nine months (mean 4.3 months) for the occlusion group and one to 12 months (mean 7.2 months) for the atropine group.

The trial reported that visual acuity in the amblyopic eye improved from baseline to a mean of $0.66 \log$ MAR units in the patching group and $0.5 \log$ MAR in the atropine group. The analyses compared pre and post-treatment visual acuity in each treatment group. No between group comparison was made. Visual acuity was 0.2 LogMAR or better (6/9 or 20/30 Snellen equivalent) in the amblyopic eye in $44.4 \%$ (8/18) of the occlusion group and $61.1 \%(11 / 18)$ of the atropine group (RR $0.73 ; 95 \%$ CI 0.39 to 1.37). Although individual patient outcome data were available, we felt unjustified to calculate the mean difference and the $95 \%$ CI for two reasons. First, three different vision charts were used to measure visual acuity (see 'Types of outcome measures'). Second, we were concerned that the visual acuity was measured at different time points for each child. We could draw limited inference from this trial regarding the relative effectiveness of patching versus atropine on visual acuity.

Secondary outcomes-The secondary outcomes of interest were examined in two trials (PEDIG 2002; Tejedor 2008). PEDIG 2002 examined stereo acuity at two-years, and Tejedor 2008 examined stereo acuity at cessation of treatment. PEDIG 2002 reported no difference between treatment groups in stereopsis. Tejedor 2008 reported the mean stereo acuity measure on Randot Preschool Stereoacuity Test was 447 seconds of arc in the optical penalization group and 403 in the atropine group at six months (MD 44.28 seconds of arc; $95 \%$ CI -100.28 to 188.84 seconds of arc).

Compliance to treatment and psychosocial impact: Complicance to treatment was reported in all three trials (Foley-Nolan 1997; PEDIG 2002; Tejedor 2008).

As part of the PEDIG trial, the Amblyopia Treatment Index questionnaire was developed to assess the psychosocial impact on the child and family of patching and atropine. The Amblyopia Treatment Index questionnaire asked questions on one of three underlying factors: adverse effects of treatment, difficulties with compliance and social stigma of the treatment. The internal-consistency reliability for the overall scale was 0.89 . The results indicated that both atropine and patching treatments were well tolerated by the child and family, although atropine received more favorable scores overall and on all three questionnaire sub-scales. The scores of the patching group were better than might have been anticipated based on the investigators' clinical experience. Patient adherence to the occlusion protocol was documented as excellent in $49 \%$ of cases compared to $78 \%$ of cases in the atropine group.

Tejedor 2008 assessed compliance to atropine penalization by dynamic retinoscopy, and in the optical penalization group "peeking over top of glasses" was documented by examiners during assessments. Non-compliance was suspected in 5/32 (15.62\%) of the optical penalization group and $4 / 31(12.9 \%)$ of the atropine group.

Foley-Nolan 1997 reported that non-compliance in the patching group was 45\% compared to only $6 \%$ in the atropine group. 
Subgroup analyses: Two trials assessed the modifying effects of baseline patient characteristics on the treatment group differences in amblyopic eye acuity (PEDIG 2002; Tejedor 2008).

PEDIG 2002 found that at six months a beneficial effect of both patching and atropine was present in all subgroups based on patient characteristics. The relative treatment effect comparing patching with atropine in each subgroup was small and clinically inconsequential. The relative treatment effect did not vary with age $(P=0.84)$, cause of amblyopia $(\mathrm{P}=0.68)$, or baseline amblyopic eye acuity $(\mathrm{P}=0.59)$. Patients with acuity of $20 / 80$ to 20/100 appeared to improve faster when a greater number of hours of patching was prescribed, but by six months, the amount of improvement was not associated with the number of hours of patching initially prescribed.

Tejedor 2008 carried out subgroup analysis to assess the effect of the type of amblyopia and the age of the participant on treatment outcomes. Subgroup analysis showed atropine to have a greater response in both strabismic and anisometropic amblyopia compared to optical penalization $(\mathrm{P}=0.02$ strabismic amblyopia; $\mathrm{P}=0.02$ anisometropic amblyopia). The response to treatment after six months was better but not significantly different in children younger than eight years compared to those eight years and over in the atropine group $(\mathrm{P}=$ $0.07)$ and the optical group $(\mathrm{P}=0.09)$.

No subgroup analysis was reported in Foley-Nolan 1997.

Economic data: The cost of the atropine regimen is less than that of the patching regimen. PEDIG 2002 estimated the cost for six months of daily patching would be about $\$ 100$ and that for atropine would be about $\$ 10$. This did not include physician visit cost.

Harms: Visual acuity in the non-amblyopic eye was the primary safety outcome of concern. PEDIG 2002 reported that at six months, visual acuity in the sound eye was decreased from baseline by 1 line in 14 participants in the patching group and 30 participants in the atropine group, and by 2 or more lines in three participants and 17 participants, respectively. Altogether, 17 participants experienced mild visual acuity reduction of the sound eye that did not require treatment in the patching group compared to 47 in the atropine group (see Table 1 'Harms of treatments at 6 months follow up in PEDIG 2002'). Only one child in the atropine group was actively treated for reduction in visual acuity in the initially sound eye. Many cases of decreased sound eye acuity in the atropine group appeared to be associated with improper refractive correction combined with a residual cycloplegic effect of the atropine (PEDIG 2002). This was supported by subsequent follow-up examinations in which 40 out of 45 participants had a same or a better visual acuity than that at baseline. Tejedor 2008 reported one case of reverse amblyopia for the atropine group. Treatment was discontinued and at further examination resolved without further intervention. Foley-Nolan 1997 found no refractive change in the sound eye of any study participant.

PEDIG 2002 also reported mild and severe skin irritation of patching treatment in 85 (41\%) and $13(6 \%)$ participants respectively. Of the atropine related harms, light sensitivity was reported in 35 (18\%) participants, lid or conjunctival irritation in eight (4\%) participants, and eye pain or headache in four (2\%) participants. One case in each group developed strabismus.

Foley-Nolan 1997 found that none of the 18 patients using atropine developed irritation of eyelids. 


\section{Discussion}

Amblyopia is the most common cause of monocular visual impairment in both children and young to middle-aged adults (Attebo 1998; Simons 1996). Occlusion therapy with patching of the sound eye has been the mainstay of amblyopia treatment, although the success of occlusion depends heavily on compliance. Occlusion therapy has been prescribed in varying regimens, ranging from a few hours a day to full-time patching, from partial occlusion to total occlusion, as a stand alone therapy, or in conjunction with another therapy. Atropine penalization has been studied in clinical trial settings as an alternative to occlusion therapy for amblyopia. This method involves instillation of atropine sulphate into the sound eye to prevent accommodation and so therefore induces blurred vision for near fixation. The accompanying dilation of the pupil also enhances this image degradation. The practical benefit of atropine penalization is its ease of administration, reliable assessment of compliance, and its relative cheapness. This systematic review aimed to identify and synthesize available RCT evidence with regard to effectiveness and safety of pharmacologic penalization compared to atropine therapy in treating amblyopia.

\section{Summary of main results}

In this systematic review, evidence from three clinical trials (one assessed as having a low risk of bias) suggests both conventional occlusion and atropine penalization produce visual acuity improvement in the amblyopic eye. Atropine penalization appears to be as effective as conventional occlusion, although the magnitude of improvement differed among the three trials.

Specifically, PEDIG 2002 found patching and atropine produce improvement in visual acuity of similar magnitude at six and 24 months. At six months, visual acuity in the amblyopic eye improved from baseline 3.16 lines in the patching group and 2.84 lines in the atropine group, and the difference between treatment groups was small and clinically inconsequential (MD $0.034 \log$ MAR; 95\% CI 0.005 to $0.064 \log \mathrm{MAR}$ ). At 24 months, additional improvement was seen in both treatment groups (3.7 lines in the patching group and 3.6 lines in the atropine group), and there continued to be no difference between groups in mean visual acuity score (MD $0.01 \log$ MAR; $95 \%$ CI -0.02 to $0.04 \log$ MAR). Tejedor 2008 reported atropine to be more effective than optical penalization. At six months, visual acuity in the amblyopic eye improved 1.8 lines in the patching group and 3.4 lines in the atropine group, and the difference between treatment groups was in favor of atropine (MD $-0.16 \log$ MAR; $95 \%$ CI -0.23 to $-0.09 \log$ MAR). However, it is difficult to compare these two trials directly due to the differing methods used for occlusion. Participants of PEDIG 2002 were prescribed total occlusion where as those in Tejedor 2008 were prescribed partial occlusion by means of optical penalization. It is unclear whether the two treatments are as effective as each other. Foley-Nolan 1997 had methodological flaws and we could not draw meaningful inference from the data reported.

Comparing across trials, although atropine was prescribed daily in PEDIG 2002 and twice weekly in Tejedor 2008, the magnitude of improvement in visual acuity in amblyopic eyes treated by atropine was comparable between these two trials. This was not unexpected. A recent trial (PEDIG 2004) has shown that weekend atropine provides a similar improvement in vision to daily atropine for participants aged between three to seven years with moderate amblyopia. Interestingly, the magnitude of improvement differed substantially in eyes treated by conventional occlusion. The inherent clinical heterogeneity between the two trials may explain some of these observed differences. First, the two trials used different patching protocols. PEDIG 2002 prescribed a minimum of six hours daily occlusion with $20 \%$ participants prescribed 12 hours over the initial six month period. Excellent compliance was documented in $49 \%$ of cases. Tejedor 2008 used partial occlusion by positive defocusing of 
the sound eye. One of the main weaknesses of this study was compliance assessment, which was not easy to address for the partial occlusion because of difficulty in reporting frequency of peeking over glasses. Therefore, it was likely the effects of partial occlusion was compromised by poor compliance. In addition, Tejedor 2008 lost $10 \%$ (7/70) of total participants. The analyses ignored issues arising from missing data. Moreover, these two trials included slightly different study populations. Children in Tejedor 2008 were one year older on average. Fifty-one per cent of children in Tejedor 2008 had strabismus as the cause of amblyopia, compared to $38 \%$ in PEDIG 2002. Baseline visual acuity in the amblyopic eye was $0.42 \log$ MAR in Tejedor 2008 and $0.51 \log$ MAR in PEDIG 2002. Older age at commencement of treatment, worse starting visual acuity, and strabismus as the cause of amblyopia have been related to poorer response to amblyopia treatment (Flynn 1998; Hiscox 1992; Newman 1996; Woodruff 1994). Therefore, these observed differences in the distribution of baseline characteristics may explain to some extent the heterogenous treatment effect observed in the conventional occlusion arm of the two trials.

With regard to binocular function, evidence from this systematic review suggested no difference between patching and atropine penalization in ocular alignment and stereo acuity. Compliance to treatment was better in atropine penalization than conventional occlusion, and both treatments were well tolerated by the child and family. Effect of treatment on visual acuity in the sound eye was comparable between two treatments. Lastly, the cost of the atropine regimen is likely to be less than that of the patching regiment, however, to date no cost-effectiveness has been carried out on the two treatment regimes.

Quality of the evidence and limitations-This review systematically synthesized evidence from randomized and quasi-randomized controlled trials for the effectiveness and safety of conventional occlusion therapy compared to pharmacological penalization in treating amblyopia. Limitations to our systematic review mainly stemmed from the clinical heterogeneity and the methodological quality of the included studies. Clinical heterogeneity was reflected in differences in the study population, including the age of participants, baseline visual acuity, cause of amblyopia, previous amblyopia treatment, and variations in the treatment regimen. In addition, except for PEDIG 2002, the trials included had some methodological flaws. Foley-Nolan 1997 was assessed as having a high risk of bias because of inadequate random sequence generation and inadequate allocation concealment. Such clinical heterogeneity and methodological limitations made it difficult to pool the effect estimates in a meta-analysis.

\section{Authors' conclusions}

\section{Implications for practice}

This systematic review provided an up-to-date summary of best available evidence for doctors, patients and other decision makers about the effectiveness and safety of conventional occlusion versus atropine penalization for treating amblyopia. Current research suggests that atropine is as effective as conventional occlusion for the treatment of amblyopia and therefore should be used as first line treatment for amblyopia. Evidence from the included trials suggests that:

- $\quad$ Atropine penalization provides an equal improvement in visual acuity as conventional occlusion for moderate amblyopia in children.

- Atropine penalization may provide a greater improvement in visual acuity compared to conventional occlusion for moderate amblyopia; however, this result should be interpreted cautiously because of the small sample size and methodological limitations of the trial. 
- There is no difference in ocular alignment and stereo acuity between atropine penalization and conventional occlusion.

- Compliance with treatment appears to be greater for those prescribed atropine penalization as opposed to conventional occlusion.

- Conventional occlusion and atropine penalization have similar reported rates of adverse event.

\section{Implications for research}

This systematic review identified key gaps in research, including:

- Long-term stability of treated amblyopia and the risk of reoccurrence of amblyopia.

- Comparision between different methods of occlusion to determine whether they are comparable, such as partial occlusion and total occlusion.

- Improved methods of documenting compliance to treatment, especially for those undergoing conventional occlusion.

- Further research into the effect of age, type of amblyopia and density of amblyopia for both atropine and conventional occlusion.

- Cost-effectiveness analyses comparing atropine penalization and conventional occlusion.

The first two topics are being investigated in ongoing studies. The results from these studies will help to clarify the long-term effectiveness and safety of atropine and occlusion therapy, as well as the relative effectiveness of partial versus total occlusion. We will update our review when results from those studies become available.

\section{Supplementary Material}

Refer to Web version on PubMed Central for supplementary material.

\section{Acknowledgments}

We acknowledge the CEVG Trials Search Co-ordinator Iris Gordon for devising and running the electronic searches. We thank Anupa Shah, Review Group Co-ordinator for CEVG, Barbara Hawkins, Ann Ervin, Sue Elliott, Sarah Hatt and the peer reviewers for their assistance and comments. We also thank Joyce Coutu and Drs. Argye Hillis and John Flynn for their many contributions to the development of the protocol. Dr. Argye Hillis also helped with screening of titles and abstracts and data abstraction for the review.

\section{Sources of support}

Internal sources

- Johns Hopkins Bloomberg School of Public Health, USA

External sources

- $\quad$ Contract N01-EY2-1003, National Eye Institute, National Institutes of Health, USA

\section{References to studies}

\section{Included studies}

Foley-Nolan 1997 Foley-Nolan A, McCann A, O'Keefe M. Atropine penalisation versus occlusion as the primary treatment for amblyopia. British Journal of Ophthalmology. 1997; 81(1):54-57.

[PubMed: 9135409] 
PEDIG 2002 Hertle RW, Scheiman MM, Beck RW, Chandler DL, Bacal DA, Birch E, et al. Pediatric Eye Disease Investigator Group. Stability of visual acuity improvement following discontinuation of amblyopia treatment in children aged 7 to 12 years. Archives of Ophthalmology. 2007; 125(5): 655-659. [PubMed: 17502505] Holmes JM, Beck RW, Kraker RT, Astle WF, Birch EE, Cole SR, et al. Pediatric Eye Disease Investigator Group. Risk of amblyopia recurrence after cessation of treatment. Journal of AAPOS. 2004; 8(5):420-428. [PubMed: 15492733] Holmes JM, Beck RW, Kraker RT, Cole SR, Repka MX, Birch EE, et al. Pediatric Eye Disease Investigator Group. Impact of patching and atropine treatment on the child and family in the amblyopia treatment study. Archives of Ophthalmology. 2003; 121(11):1625-1632. [PubMed: 14609923] Repka MX, Kraker RT, Beck RW, Holmes JM, Cotter SA, Birch EE, et al. Pediatric Eye Disease Investigator Group. A randomized trial of atropine vs patching for treatment of moderate amblyopia: follow-up at age 10 years. Archives of Ophthalmology. 2008; 126(8):1039-1044. [PubMed: 18695096] Pediatric Eye Disease Investigator Group. A comparison of atropine and patching treatments for moderate amblyopia by patient age, cause of amblyopia, depth of amblyopia, and other factors. Ophthalmology. 2003; 110(8):1632-1637. [PubMed: 12917184] Pediatric Eye Disease Investigator Group. A randomized trial of atropine vs. patching for treatment of moderate amblyopia in children. Archives of Ophthalmology. 2002; 120(3):268-278. [PubMed: 11879129] Pediatric Eye Disease Investigator Group. The clinical profile of moderate amblyopia in children younger than 7 years. Archives of Ophthalmology. 2002; 120(3):281-287. [PubMed: 11879130] Pediatric Eye Disease Investigator Group. The course of moderate amblyopia treated with atropine in children: experience of the amblyopia treatment study. American Journal of Ophthalmology. 2003; 136(4):630-639. [PubMed: 14516802] Pediatric Eye Disease Investigator Group. The course of moderate amblyopia treated with patching in children: experience of the amblyopia treatment study. American Journal of Ophthalmology. 2003; 136(4):620-629. [PubMed: 14516801] Repka MX, Melia M, EibschitzTsimhoni M, London R, Magoon E. Pediatric Eye Disease Investigator Group. The effect on refractive error of unilateral atropine as compared with patching for the treatment of amblyopia. Journal of AAPOS. 2007; 11(3):300-302. [PubMed: 17572346] Repka MX, Holmes JM, Melia BM, Beck RW, Gearinger MD, Tamkins SM, et al. Pediatric Eye Disease Investigator Group. The effect of amblyopia therapy on ocular alignment. Journal of AAPOS. 2005; 9(6):542-545. [PubMed: 16414520] Repka MX, Wallace DK, Beck RW, Kraker RT, Birch EE, Cotter SA, et al. Pediatric Eye Disease Investigator Group. Twoyear follow-up of a 6-month randomized trial of atropine vs patching for treatment of moderate amblyopia in children. Archives of Ophthalmology. 2005; 123(2):149-157. [PubMed: 15710809]

Tejedor 2008 Published and unpublished data [ISRCTN: ISRCTN89210627] Tejedor J, Ogallar C. Comparative efficacy of penalization methods in moderate to mild amblyopia. American Journal of Ophthalmology. 2008; 145(3):562-569. [PubMed: 18207121]

\section{Excluded studies}

Chatzistefanou 2000 Chatzistefanou KI, Mills MD. The role of drug treatment in children with strabismus and amblyopia. Paediatric Drugs. 2000; 2(2):91-100. [PubMed: 10937461]

Cole 2001 Cole SR, Beck RW, Moke PS, Celano MP, Drews CD, Repka MX, et al. Pediatric Eye Disease Investigator Group. The Amblyopia Treatment Index. Journal of AAPOS. 2001; 5(4):250254. [PubMed: 11507585]

Sheiman 2005 Scheiman MM, Hertle RW, Beck RW, Edwards AR, Birch E, Cotter SA, et al. Pediatric Eye Disease Investigator Group. Randomized trial of treatment of amblyopia in children aged 7 to 17 years. Archives of Ophthalmology. 2005; 123(4):437-447. [PubMed: 15824215]

Wu $2006 \mathrm{Wu}$ C, Hunter DG. Amblyopia: diagnostic and therapeutic options. American Journal of Ophthalmology. 2006; 141(1):175-184. [PubMed: 16386994]

\section{Studies awaiting classification}

Menon 2008 Menon V, Shailesh G, Sharma P, Saxena R. Clinical trial of patching versus atropine penalization for the treatment of anisometropic amblyopia in older children. Journal of AAPOS. 2008; 12(5):493-497. [PubMed: 18534880]

PEDIG 2008 [ClinicalTrials.gov: NCT00315328] Scheiman MM, Hertle RW, Kraker RT, Beck RW, Birch EE, Felius J, et al. Pediatric Eye Disease Investigator Group. Patching vs atropine to treat 
amblyopia in children aged 7 to 12 years: a randomized trial. Archives of Ophthalmology. 2008; 126(12):1634-1642. [PubMed: 19064841]

Yan 2008 Yan JJ, Peng HC, Wu CX, Liu ZY, Wang YF. A clinical trial of atropine penalization vs patching for treatment of monocular amblyopia. International Journal of Ophthalmology. 2008; 8(4):777-778.

\section{Other references}

\section{Additional references}

AAO 2007 American Academy of Ophthalmology Pediatric Ophthalmology/Strabismus Panel. Preferred Practice Pattern ${ }^{\circledR}=$ Guidelines. Amblyopia. http://www.aao.org/ppp.

Ansons 2001 Ansons A, Davis H. Diagnosis and Management of Ocular Motility Disorders (3rd edition). 2001OxfordBlackwell Science

Antonio-Santos 2006 Antonio-Santos A, Vedula SS, Hatt SR, Powell C. Interventions for stimulus deprivation amblyopia. Cochrane Database of Systematic Reviews. 2006; (Issue 3) Art. No.: CD005136.

AOA 1997 Rouse MW, Cooper JS, Cotter SA, Press LJ, Tannen BM. Care Of the patient with amblyopia: reference guide for clinicians. $1997 \mathrm{http}: / / \mathrm{www}$.aoa.org/documents/CPG-4.pdf.

Attebo 1998 Attebo K, Mitchell P, Cumming R, Smith W, Jolly N, Sparkes R. Prevalence and causes of amblyopia in an adult population. Ophthalmology. 1998; 105(1):154-159. [PubMed: 9442792]

Brown 2000 Brown SA, Weih LM, Fu CL, Dimitrov P, Taylor HR, McCarty CA. Prevalence of amblyopia and associated refractive errors in an adult population in Victoria, Australia. Ophthalmic Epidemiology. 2000; 7(4):249-258. [PubMed: 11262672]

Ciuffreda 1991 Ciuffreda KJ, Levis DM, Selenow A. Amblyopia: basic and clinical aspects. 1991BostonButterworth-Heinemann

Deeks 2008 Deeks JJ, Higgins JPT, Altman DG, Higgins JPT, Green S. Chapter 9: Analysing data and undertaking meta-analyses. Cochrane Handbook for Systematic Reviews of Interventions Version 5.0.1. 2008updated September 2008The Cochrane CollaborationAvailable from www.cochranehandbook.org.

Fells 1990 Fells P. Richardson Cross Lecture 1989 amblyopia-an historical perspective. Eye. 1990; 4(Pt 6):775-786. [PubMed: 2101107]

Flom 1985 Flom MC, Bedell HE. Identifying amblyopia using associated conditions, acuity, and nonacuity features. American Journal of Optometry and Physiological Optics. 1985; 62(3):153160. [PubMed: 3985107]

Flynn 1998 Flynn JT, Schiffman J, Feuer W, Corona A. The therapy of amblyopia: an analysis of the results of amblyopia therapy utilizing the pooled data of published studies. Transactions of American Ophthalmological Society. 1998; 96:431-450.

Glanville 2006 Glanville JM, Lefebvre C, Miles JN, Camosso-Stefinovic J. How to identify randomized controlled trials in MEDLINE: ten years on. Journal of the Medical Library Association. 2006; 94(2):130-136. [PubMed: 16636704]

Higgins 2008 Higgins JPT, Altman DG, Higgins JPT, Green S. Chapter 8: Assessing risk of bias in included studies. Cochrane Handbook for Systematic Reviews of Interventions. Version 5.0.1. 2008updated September 2008The Cochrane CollaborationAvailable from www.cochranehandbook.org.

Hiscox 1992 Hiscox F, Strong N, Thompson JR, Minshull C, Woodruff G. Occlusion for amblyopia: a comprehensive survey of outcome. Eye. 1992; 6(3):300-304. [PubMed: 1446765]

Jones 2003 Jones D, Westall C, Averbeck K, Abdolell M. Visual acuity assessment: a comparison of two tests for measuring children's vision. Ophthalmic \& Physiological Optics. 2003; 23(6):541546. [PubMed: 14622358]

Kaye 2002 Kaye SB, Chen SI, Price G, Kaye LC, Noonan C, Tripathi A, et al. Combined optical and atropine penalization for the treatment of strabismic and anisometropic amblyopia. Journal of AAPOS. 2002; 6(5):289-293. [PubMed: 12381987] 
Levi 2006 Levi DM. Visual processing in amblyopia: human studies. Strabismus. 2006; 14(1):11-19. [PubMed: 16513566]

Moseley 2002 Moseley MJ, Neufield M, McCarry B, Charnock A, McNamara R, Rice T, et al. Remediation of refractive amblyopia by optical correction alone. Ophthalmic \& Physiological Optics. 2002; 22(4):296-299. [PubMed: 12162480]

Newman 1996 Newman DK, Hitchcock A, McCarthy H, Keast-Butler J, Moore AT. Preschool vision screening: outcome of children referred to the hospital eye service. British Journal of Ophthalmology. 1996; 80(12):1077-1082. [PubMed: 9059274]

Newsham 2000 Newsham D. Parental non-concordance with occlusion therapy. British Journal of Ophthalmology. 2000; 84(9):957-962. [PubMed: 10966944]

PEDIG 2004 Repka MX, Cotter SA, Beck RW, Kraker RT, Birch EE, Everett DF, et al. Pediatric Eye Disease Investigator Group. A randomized trial of atropine regimens for treatment of moderate amblyopia in children. Ophthalmology. 2004; 111(11):2076-2085. [PubMed: 15522375]

PEDIG 2006 Wallace DK, Edwards AR, Cotter SA, Beck RW, Arnold RW, et al. Pediatric Eye Disease Investigator Group. A randomized trial to evaluate 2 hours of daily patching for strabismic and anisometropic amblyopia in children. Ophthalmology. 2006; 113(6):904-912. [PubMed: 16751033]

Rahi 2002 Rahi J, Logan S, Timms C, Russell-Eggitt I, Taylor D. Risks, causes and outcomes of visual impairment after loss of vision in the non-amblyopic eye: a population based study. Lancet. 2002; 360(9333):597-602. [PubMed: 12241931]

Repka 1993 Repka MX, Ray JM. The efficacy of optical and pharmacological penalization. Ophthalmology. 1993; 100(5):769-775. [PubMed: 8493022]

Shotton 2008a Shotton K, Elliott S. Interventions for strabismic amblyopia. Cochrane Database of Systematic Reviews. 2008; (Issue 2) Art. No.: CD006461.

Shotton $2008 b$ Shotton K, Powell C, Voros G, Hatt SR. Interventions for unilateral refractive amblyopia. Cochrane Database of Systematic Reviews. 2008; (Issue 4) Art. No.: CD005137.

Simons 1996 Simons K. Preschool vision screening: rationale, methodology and outcome. Survey of Ophthalmology. 1996; 41(1):3-30. [PubMed: 8827927]

Simons 1997 Simons K, Stein L, Sener EC, Vitale S, Guyton DL. Full-time atropine, intermittent atropine, and optical penalization and binocular outcome in treatment of strabismic amblyopia. Ophthalmology. 1997; 104(12):2145-2155.

Simons 1999 Simons K, Preslan M. Natural history of amblyopia owing to lack of compliance. British Journal of. Ophthalmology. 1999; 83(5):582-587.

Simons 2005 Simons K. Amblyopia characterization, treatment, and prophylaxis. Survey of Ophthalmology. 2005; 50(2):123-166. [PubMed: 15749306]

Swann 1974 Swann AP, Hunter CD. A survey of amblyopia treated by atropine occlusion. British Orthoptic Journal. 1974; 31:65-69.

Tommila 1981 Tommila V, Tarkkannen A. Incidence of loss of vision in the healthy eye in amblyopia. British Journal of Ophthalmology. 1981; 65(8):575-577. [PubMed: 7295619]

Williams 2002 Williams C, Northstone K, Harrad RA, Sparrow JM, Harvey I. ALSPAC Study Team. Amblyopia treatment outcomes after screening before or at age 3 years: follow up from randomised trial. BMJ. 2002; 324(7353):1549. [PubMed: 12089090]

Woodruff 1994 Woodruff F, Hiscox F, Thompson JR, Smith LK. Factors affecting the outcome of children treated for amblyopia. Eye. 1994; 8(Pt 6):627-631. [PubMed: 7867817]

Wu $2006 \mathrm{Wu}$ C, Hunter DG. Amblyopia: diagnostic and therapeutic options. American Journal of Ophthalmology. 2006; 141(1):175-184. [PubMed: 16386994]

\title{
Appendices
}

\section{CENTRAL search strategy}

\author{
\#1 MeSH descriptor Amblyopia \\ \#2 amblyop*
}


\#3 MeSH descriptor Strabismus

\#4 strabism*

\#5 squint*

\#6 MeSH descriptor Refractive Errors

\#7 refractive near error*

\#8 MeSH descriptor Anisometropia

\#9 anisometropi*

\#10 lazy eye*

\#11 (\#1 OR \#2 OR \#3 OR \#4 OR \#5 OR \#6 OR \#7 OR \#8 OR \#9 OR \#10)

\#12 occlu*

\#13 patch*

\#14 shield*

\#15 (\#12 OR \#13 OR \#14)

\#16 MeSH descriptor Atropine

\#17 atropine*

\#18 (\#16 OR \#17)

\#19 (\#11 AND \#15 AND \#18)

\section{MEDLINE search strategy}

1. randomized controlled trial.pt.

2. (randomized or randomised) ab,ti.

3. placebo.ab,ti.

4. dt.fs.

5. randomly.ab,ti.

6. trial.ab,ti.

7. groups.ab,ti.

8. or/1-7

9. exp animals/

10. exp humans/

11. 9 not (9 and 10)

12. 8 not 11

13. exp amblyopia/

14. amblyop\$.tw.

15. exp strabismus/

16. strabism $\$ . t w$.

17. squint\$.tw. 
18. exp refractive error/

19. (refractive adj2 error\$).tw.

20. exp anisometropia/

21. anisometropi $\$ . t w$.

22. lazy eye\$.tw.

23. or/13-22

24. occlu\$.tw.

25. patch $\$ . t w$.

26. shield\$.tw.

27. or/24-26

28. exp atropine/

29. atropine $\$ . t w$.

30. or $/ 28-29$

31. 23 and 27 and 30

32. 12 and 31

The search filter for trials at the beginning of the MEDLINE strategy is from the published paper by Glanville et al (Glanville 2006).

\section{EMBASE search strategy}

1. exp randomized controlled trial/

2. exp randomization/

3. exp double blind procedure/

4. exp single blind procedure/

5. random $\$ . t w$.

6. or $/ 1-5$

7. (animal or animal experiment).sh.

8. human.sh.

9. 7 and 8

10. 7 not 9

11. 6 not 10

12. exp clinical trial/

13. (clin $\$$ adj3 trial\$).tw.

14. ((singl\$ or doubl\$ or trebl\$ or tripl\$) adj3 (blind $\$$ or mask $\$))$.tw.

15. exp placebo/

16. placebo\$.tw.

17. random $\$ . t w$. 
18. exp experimental design/

19. exp crossover procedure/

20. exp control group/

21. exp latin square design/

22. or $/ 12-21$

23. 22 not 10

24. 23 not 11

25. exp comparative study/

26. exp evaluation/

27. exp prospective study/

28. (control\$ or prospectiv\$ or volunteer\$).tw.

29. or $/ 25-28$

30. 29 not 10

31. 30 not (11 or 23$)$

32. 11 or 24 or 31

33. exp amblyopia/

34. amblyop\$.tw.

35. exp strabismus/

36. strabism $\$ . t w$.

37. squint $\$ . t w$.

38. exp refractive error/

39. (refractive adj2 error\$).tw.

40. exp anisometropia/

41. anisometropi\$.tw.

42. lazy eye\$.tw.

43. or $/ 33-42$

44. occlu\$.tw.

45. patch\$.tw.

46. shield\$.tw.

47. or/44-46

48. exp atropine/

49. atropine $\$ . t w$.

50. or $/ 48-49$

51. 43 and 47 and 50

52. 32 and 51 


\section{LILACS search strategy}

amblyopia or strabism\$ or squint\$ and patch\$ or occlu\$ or shield\$ and atropine\$

\section{WHO ICTRP}

amblyopia 


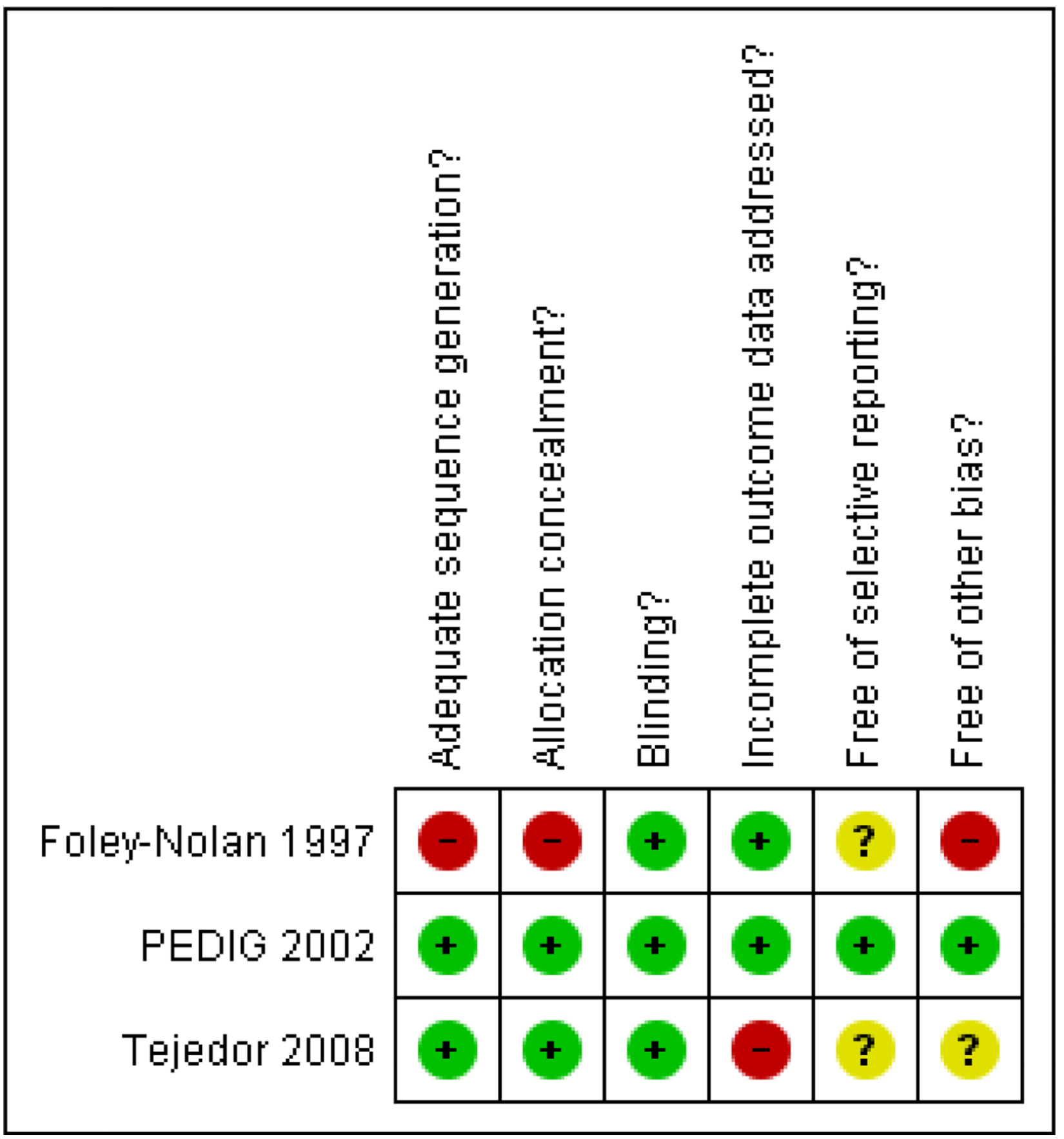

Figure 1.

Methodological quality summary: review authors' judgements about each methodological quality item for each included study. 


\section{Summary of findings tables Additional tables}

\section{Harms of treatments at 6 months follow up in PEDIG 2002}

\begin{tabular}{|c|c|c|}
\hline Reported harms & $\begin{array}{l}\text { Patching } \mathbf{n} / \mathbf{N} \\
(\%)\end{array}$ & $\begin{array}{l}\text { Atropine } \mathbf{n} / \mathbf{N} \\
(\%)\end{array}$ \\
\hline Mild reduction in visual acuity of the non-amblyopic eye not requiring treatment & $17 / 208(8.2 \%)$ & $47 / 194(24.2 \%)$ \\
\hline Severe reduction in visual acuity of the non-amblyopic eye requiring treatment & $0 / 208(0 \%)$ & $1 / 194(0.5 \%)$ \\
\hline Mild skin irritation not requiring treatment & $85 / 208(41.0 \%)$ & NA \\
\hline Moderate to severe skin irritation & $13 / 208(6.0 \%)$ & NA \\
\hline Light sensitivity & NA & $35 / 194(18.0 \%)$ \\
\hline Lid or conjunctival irritation & NA & $8 / 194(4.1 \%)$ \\
\hline Eye pain or headaches & NA & $4 / 194(2.1 \%)$ \\
\hline Developed strabismus & $1 / 208(0.5 \%)$ & $1 / 194(0.5 \%)$ \\
\hline Ocular deviation of more than $8 \triangle$ & $1 / 208(0.5 \%)$ & $1 / 194(0.5 \%)$ \\
\hline Among participants who had a pre-existing esotropia that increased by more than $10 \triangle$ & 2 & 3 \\
\hline $\begin{array}{l}\text { Among participants with no distance ocular deviation at baseline, a small-angle strabismus (1 to } 8 \triangle \text { ) at } \\
\text { distance fixation }\end{array}$ & $12 / 97(12.3 \%)$ & $11 / 90(12.2 \%)$ \\
\hline
\end{tabular}

Footnotes

NA: Not applicable 


\section{Characteristics of studies}

\section{Characteristics of included studies}

\begin{tabular}{|c|c|c|}
\hline \multicolumn{3}{|l|}{ Foley-Nolan 1997} \\
\hline Methods & \multicolumn{2}{|c|}{$\begin{array}{l}\text { Study design: CCT } \\
\text { Number randomized: } 36 \text { (18 in the occlusion group; } 18 \text { in the atropine penalization group) } \\
\text { Unit of randomization: one eye per participant was randomized. } \\
\text { Number analyzed: } 36 \\
\text { Number of centers: } 1 \\
\text { Date of first enrolment: January } 1994 \\
\text { Length of follow-up: planned: unclear; actual: unclear } \\
\text { Sample size estimation: not reported }\end{array}$} \\
\hline Participants & \multicolumn{2}{|c|}{$\begin{array}{l}\text { - } \\
\text { - } \\
\text { - Sge: mean }=5.5 \text { years; range }=2.5 \text { to } 9 \text { years } \\
\text { - Key inclusion criteria: any type or level of amblyopia; no previous treatment for amblyopia } \\
\text { - Key exclusion criteria: not reported } \\
\text { - Frequency of strabismus as the cause of amblyopia: } 92 \% \text { (including participants affected by } \\
\text { combined mechanism amblyopia) } \\
\text { - Baseline visual acuity in the amblyopic eye: } 0.92 \text { logMAR in atropine penalization group; } 1 \\
\text { logMAR in occlusion group. } \\
\text { - Comparability of baseline characteristics: comparable }\end{array}$} \\
\hline Interventions & \multicolumn{2}{|c|}{$\begin{array}{l}\text { - Intervention regimen \#1: occlusive patch placed over non-amblyopic eye. Regimen of } \\
\text { occlusion varies by age and level of amblyopia. Full time occlusion was instigated for } 1 \text { week } \\
\text { per year of life. Once vision improved to 6/9 or better occlusion was reduced to half day. } \\
\text { Patients monitored weekly per year of life. Treatment was concluded when a visual acuity of } \\
6 / 6 \text { was achieved, or when visual acuity remained static over three successive assessments. } \\
\text { Intervention regimen \#2: atropine drops } 1 \% \text { instilled daily (every morning) into non-amblyopic } \\
\text { eye. Follow-up visits approximately once a month. Treatment was concluded when a visual } \\
\text { acuity of } 6 / 6 \text { was achieved, or when visual acuity remained static over three successive } \\
\text { assessments. }\end{array}$} \\
\hline Outcomes & \multicolumn{2}{|c|}{$\begin{array}{l}\text { Visual acuity assessed using the Snellen chart, Kay's Pictures, or Sheridan-Gardener test types, } \\
\text { depending on the age and comprehension of the patient. } \\
\text { Refractive error examined by cycloplegic retinoscopy } 35 \text { minutes after instillation of } 1 \% \\
\text { cyclopentolate. }\end{array}$} \\
\hline Notes & \multicolumn{2}{|c|}{$\begin{array}{l}\text { Funding sources: none declared } \\
\text { Statistical analyses: inappropriate (no between group comparison was made) } \\
\text { Subgroup analyses: none reported }\end{array}$} \\
\hline \multicolumn{3}{|l|}{ Risk of bias table } \\
\hline Item & Authors' judgement & Support for judgement \\
\hline Adequate sequence generation? & No & $\begin{array}{l}\text { "All new patients due to commence treatment for } \\
\text { amblyopia were allocated either to treatment with } \\
\text { atropine penalization, or to occlusion therapy. This was } \\
\text { achieved on a strict alternate patient basis." }\end{array}$ \\
\hline Allocation concealment? & No & $\begin{array}{l}\text { "Appointments were organized by an independent } \\
\text { observer (clinic sister) in order to prevent any possibility } \\
\text { of bias being introduced." }\end{array}$ \\
\hline
\end{tabular}




\begin{tabular}{|l|l|l|} 
Blinding? & Yes & $\begin{array}{l}\text { "The visual acuity assessors were masked to patient } \\
\text { treatment." }\end{array}$ \\
\hline $\begin{array}{l}\text { Incomplete outcome data } \\
\text { addressed? }\end{array}$ & Yes & No lost to follow up. \\
\hline Free of selective reporting? & Unclear & Insufficient information to assess. \\
\hline Free of other bias? & No & $\begin{array}{l}\text { Sample size was very small to detect any meaningful } \\
\text { difference. } \\
\text { Inappropriate statistical analyses. }\end{array}$ \\
\hline
\end{tabular}

\section{PEDIG 2002}

Methods

- $\quad$ Study design: RCT

- Number randomized: 419 (215 in the occlusion group; 204 in the atropine penalization group). Based on a post randomization review, 10 patients ( 3 in the occlusion and 7 in the atropine group) did not fully meet the eligibility criteria.

- Unit of randomization: one eye per participant was randomized

- $\quad$ Number analyzed: 419

- Number of centers: 47 (number of patients enrolled per site ranged from 1 to 35 , median= 5 patients)

- Date of first enrolment: April, 1999

- Length of follow-up: planned: 2 years; actual: 2 years

- Sample size estimation: the sample size was based on whether the visual improvement at 6 months with atropine was equivalent to that with patching (equivalent level of the $95 \% \mathrm{CI}$ for the difference in mean visual acuity between groups was set to be 0.1 logMAR unit; power $=80 \%$ and $\mathrm{a}=0.05$ for assessments of the treatment group differences in each of 3 subgroups based on cause of amblyopia). With the sample size estimated $n=400$, the power for the primary overall analysis was $99 \%$.

\section{- Country: United States}

- Age (mean $\pm \mathrm{SD}): 5.3 \pm 1.1$ years

- Sex: $47 \%$ were girls

- $\quad$ Key inclusion criteria: age $<7$; able to measure visual acuity using the Amblyopia Treatment Study Visual Acuity testing protocol; visual acuity in the amblyopic eye $\leqq 20 / 40$ and $\geqq$ $20 / 100$; visual acuity in the sound eye $\geqq 20 / 40$; inter eye acuity difference $\geqq 3 \operatorname{logMAR}$ lines; no more than 2 months of amblyopia therapy in the past 2 years; refractive error corrected for at least 4 weeks; amblyopia associated with strabismus, refractive error/anisometropia, or both

- $\quad$ Key exclusion criteria: presence of an ocular cause for reduced visual acuity; prior intraocular surgery; myopia (spherical equivalence of $-0.50 \mathrm{D}$ or more) in either eye; Down syndrome; known skin reaction to patch or bandage adhesive, or allergy to atropine or other cycloplegics

- Frequency of strabismus as the cause of amblyopia: $38 \%$

- Baseline visual acuity in the amblyopic eye:0.53 $\log$ MAR in atropine penalization group; 0.52 $\log$ MAR in occlusion group

- Comparability of baseline characteristics: comparable

Interventions

- Intervention regimen \#1: Conventional occlusion prescribed for minimum of 6 hours daily and maximum all waking hours. This continued for full 6 months unless occlusion amblyopia developed. When criteria for successful result met, occlusion was then reduced but needed to be minimum of 7 hours per week. Where there was visual acuity difference of 1 line. When equal visual acuity achieved occlusion was stopped. If criteria for successful treatment were not met by the 16-week visit, and patching time had been less than 12 hours per day, patching time was increased to 12 or more hours per day for 2 months prior to the 6-month outcome examination. Adhesive skin patches provided by the study (Coverlet Eye Occlusors; Beiersdorf-Jobst Inc, Rutherford College, NC) were used unless there was skin allergy or irritation non-responsive to both local treatment with a skin emollient and a change in the brand of patch, in which case a spectacle occluder could be prescribed.

- Intervention regimen \#2: 1 drop per day of atropine sulphate 1\%. Daily use continued until successful visual acuity outcomes achieved. Atropine could then reduced to twice weekly or discontinued. For patients with hyperopia in the sound eye, if the amblyopic eye was not successfully treated by the 16-week visit, the spectacle lens was reduced to plano for 2 months

Cochrane Database Syst Rev. Author manuscript; available in PMC 2013 October 21. 


\begin{tabular}{|c|c|c|}
\hline & \multicolumn{2}{|c|}{$\begin{array}{l}\text { prior to the 6-month outcome examination. If allergy development treatment was changed to } \\
5 \% \text { homatropine. }\end{array}$} \\
\hline Outcomes & \multicolumn{2}{|c|}{$\begin{array}{l}\text { Primary outcome: amblyopic eye visual acuity score in logMAR units measured using } \\
\text { Amblyopia Treatment Study visual acuity testing protocol at } 6 \text { months. } \\
\text { Secondary outcomes: a) treatment success defined as a 6-month visual acuity of 20/30 or better } \\
\text { and/or improved from baseline by } 3 \text { or more lines (A patient was classified as a treatment } \\
\text { failure if the success criteria were not met or if the non-assigned treatment was received for at } \\
\text { least } 1 \text { week.); b) amblyopic eye visual acuity score in logMAR units at 2-year; c) visual acuity } \\
\text { in the sound eye at 2-year; d) ocular alignment at 2-year; e) stereo acuity at 2-year. }\end{array}$} \\
\hline Notes & \multicolumn{2}{|c|}{$\begin{array}{l}\text { - Funding sources: National Eye Institute, National Institute of Health, Bethesda, Maryland, } \\
\text { USA. Companies provided materials at a discount for the study: Precision Vision (near acuity } \\
\text { test), Stereo Optical Co inc (Stereoacuity tests), Beiersdorf-Jobst Inc (Coverlet Eye Occlusors), } \\
\text { and Bausch and Lomb Pharmaceuticals Inc (atropine). } \\
\text { - Statistical analyses: appropriate } \\
\text { - Subgroup analyses: reported }\end{array}$} \\
\hline \multicolumn{3}{|l|}{ Risk of bias table } \\
\hline Item & Authors' judgement & Support for judgement \\
\hline Adequate sequence generation? & Yes & $\begin{array}{l}\text { "Randomization was accomplished on the study's web } \\
\text { site using a permuted-blocks design of varying block } \\
\text { sizes with a separate sequence of computer-generated } \\
\text { random numbers for each investigator." }\end{array}$ \\
\hline Allocation concealment? & Yes & $\begin{array}{l}\text { "Randomization was accomplished on the study's web } \\
\text { site", which is one form of central allocation. }\end{array}$ \\
\hline Blinding? & Yes & $\begin{array}{l}\text { "At the 6-month outcome examination, visual acuity } \\
\text { testing of the amblyopic eye was conducted by a tester } \\
\text { masked to the patient's treatment group. To conceal the } \\
\text { treatment group assignment, a patch was placed over the } \\
\text { sound eye by site staff prior to the examination to avoid } \\
\text { unmasking either from a dilated pupil due to atropine or } \\
\text { from skin changes due to patching." } \\
\text { "At the 2-year examination, a tester masked to the } \\
\text { patient's treatment group conducted visual acuity testing." } \\
\text { The vision tester was masked to treatment group for } 97 \% \\
\text { of these examinations at } 6 \text { months, and } 92 \% \text { at } 24 \\
\text { months. }\end{array}$ \\
\hline $\begin{array}{l}\text { Incomplete outcome data } \\
\text { addressed? }\end{array}$ & Yes & $\begin{array}{l}\text { At 6-months: } \\
\text { Patching group: } 7 \text { dropped out in total ( } 4 \text { lost to follow- } \\
\text { up, } 3 \text { were withdrawn at the request of the parent); } \\
208 / 215=97 \% \text { completed. Atropine group: } 10 \text { dropped } \\
\text { out in total ( } 6 \text { lost to follow-up, } 4 \text { were withdrawn at the } \\
\text { request of the parent); } 194 / 204=95 \% \text { completed. } \\
\text { "All analyses followed the intention-to-treat principle." } \\
\text { "Patients were included in the primary analysis if they } \\
\text { had a visual acuity measurement in the amblyopic eye } \\
\text { within the time window of the } 6 \text {-month visit or, in the } \\
\text { absence of such a visit, if they had a visual acuity } \\
\text { measurement that was no more than } 1 \text { month before or } 3 \\
\text { months after this window. Two additional analyses were } \\
\text { conducted on the 6-month amblyopic eye logMAR acuity } \\
\text { scores: one analysis included only patients who had an } \\
\text { examination within the 6-month window, and the other } \\
\text { analysis included all patients using the method of last } \\
\text { observation carried forward to impute for missing data } \\
\text { (for patients missing the outcome examination, the visual } \\
\text { acuity recorded at the last follow-up examination was } \\
\text { used; for patients with no follow-up, the baseline acuity } \\
\text { was used). Results of these } 2 \text { analyses were similar to the } \\
\text { primary analysis (data not shown)." }\end{array}$ \\
\hline Free of selective reporting? & Yes & Not found \\
\hline Free of other bias? & Yes & Not found \\
\hline
\end{tabular}




\begin{tabular}{|c|c|c|}
\hline Methods & \multicolumn{2}{|c|}{$\begin{array}{l}\text { - Unit of randomization: one eye per participant was randomized } \\
\text { - Number analyzed: } 63 \\
\text { - } \\
\text { - } \quad \text { Dumber of centers: } 1 \\
\text { - } \quad \text { Length of follow-up: planned: } 6 \text { months; actual: } 6 \text { months. } \\
\text { - Sample size estimation: the sample size was based on } 0.1 \text { logMAR units difference between } \\
\text { the two groups in change in visual acuity of the amblyopic eye, a standard deviation of } 0.15 \text {, } \\
\text { and a type I error of } 5 \% \text {. With the sample size estimated of } 70 \text {, the power for the primary } \\
\text { overall analysis was } 98 \% \text {. }\end{array}$} \\
\hline Participants & 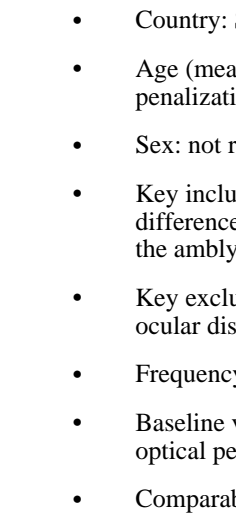 & $\begin{array}{l}\text { the atropine group; } 6.25 \pm 2.11 \text { years in the optical } \\
\text { a or strabismic amblyopia; } 2 \text { to } 10 \text { years; interocular } \\
\text { ast two logMAR lines ( } 0.2 \text { logMAR units); visual acuity in } \\
\text { ogMAR } \\
\text { have been previously treated for amblyopia; organic } \\
\text { gery or botulinum treatment; mixed amblyopia } \\
\text { e of amblyopia: } 51 \% \\
\text { opic eye: } 0.41 \text { logMAR in atropine group; } 0.44 \log \text { MAR in } \\
\text { istics: comparable }\end{array}$ \\
\hline Interventions & \multicolumn{2}{|c|}{$\begin{array}{l}\text { - Intervention regimen \#1: optical penalization was achieved by positive defocus of the sound } \\
\text { eye (overplus glass). Sphere was added until vision in the sound eye was blurred to the same } \\
\text { level as that of the amblyopic eye. Minimal amount of sphere needed was prescribed. Optical } \\
\text { penalization was readjusted if necessary in every follow-up visit. Defocus was discontinued } \\
\text { when visual acuity remained equal in the amblyopic and sound eye for two consecutive visits. } \\
\text { Intervention regimen \#2: } 1 \% \text { atropine (Colircusi Atropina 1\%; AlconCusi, Barcelona, Spain) } \\
\text { twice weekly when interocular acuity difference was present, and once weekly for maintenance } \\
\text { therapy (equal visual acuity in both eyes) until the next follow-up visit. Atropine was } \\
\text { withdrawn when visual acuity remained equal in the amblyopic and sound eye on two } \\
\text { consecutive follow-up visits. Atropine was discontinued when allergy or intolerance occurred } \\
\text { or when reverse amblyopia was suspected. }\end{array}$} \\
\hline Outcomes & \multicolumn{2}{|c|}{$\begin{array}{l}\text { measured using the logMAR Crowded Glasgow acuity cards } \\
\text { Secondary outcomes: sensory status determined by stereo acuity measurement using the } \\
\text { Titmus fly test and Randot pre-school or Randot circles stereo acuity test }\end{array}$} \\
\hline Notes & \multicolumn{2}{|c|}{$\begin{array}{ll}\text { - } & \text { Funding sources: Fundación De Investigación Biomédica, Hospital Ramón Y Cajal, Madrid, } \\
\text { Spain } \\
\text { - } & \text { Statistical analyses: appropriate } \\
\text { - } & \text { Subgroup analyses: based on types of amblyopia }\end{array}$} \\
\hline \multicolumn{3}{|l|}{ Risk of bias table } \\
\hline Item & Authors' judgement & Support for judgement \\
\hline Adequate sequence generation? & Yes & $\begin{array}{l}\text { "Participants were randomized to atropine or optical } \\
\text { defocus, after stratification into two groups according to } \\
\text { cause of amblyopia using a computer-generated sequence } \\
\text { of random numbers, by the steering committee." }\end{array}$ \\
\hline
\end{tabular}




\begin{tabular}{|l|l|l|} 
Allocation concealment? & Yes & $\begin{array}{l}\text { "In this study a central office steering committee handled } \\
\text { the randomization process so that investigators who } \\
\text { determined eligibility and enrolled individuals were } \\
\text { unaware of the assignment order." (Information source: } \\
\text { personal contact with the lead investigator) }\end{array}$ \\
\hline Blinding? & Yes & $\begin{array}{l}\text { "Observers who measured visual acuity were masked to } \\
\text { the treatment group. The reported success of blinding in } \\
90.6 \%(29 / 32) \text { of the optical and 87\% (27/31) of the } \\
\text { pharmacologic penalization groups." }\end{array}$ \\
\hline $\begin{array}{l}\text { Incomplete outcome data } \\
\text { addressed? }\end{array}$ & No & $\begin{array}{l}\text { Three lost follow-up in penalization group; two } \\
\text { discontinued treatment in the atropine group because of } \\
\text { intolerance, one was withdrawn and one lost follow-up. } \\
\text { Those seven participants were excluded from the } \\
\text { analyses. }\end{array}$ \\
\hline Free of selective reporting? & Unclear & Insufficient information to assess. \\
\hline Free of other bias? & Unclear & Unclear \\
\hline
\end{tabular}

Footnotes

PEDIG: Pediatric Eye Disease Investigator Group 


\section{Characteristics of excluded studies}

\begin{tabular}{|l|l|l|}
\hline \multicolumn{2}{|l|}{ Chatzistefanou 2000} \\
\hline Reason for exclusion & Not a randomized controlled trial: narrative review article \\
\hline Cole 2001 & Not a randomized controlled trial: development of a questionnaire \\
\hline Reason for exclusion & Sheiman 2005 & $\begin{array}{l}\text { Not the comparison of interest: participants received optical correction combined with atropine or optical correction } \\
\text { alone. }\end{array}$ \\
\hline Reason for exclusion \\
\hline Wu 2006
\end{tabular}


Characteristics of studies awaiting classification

\begin{tabular}{|c|c|}
\hline \multicolumn{2}{|l|}{ Menon 2008} \\
\hline Methods & 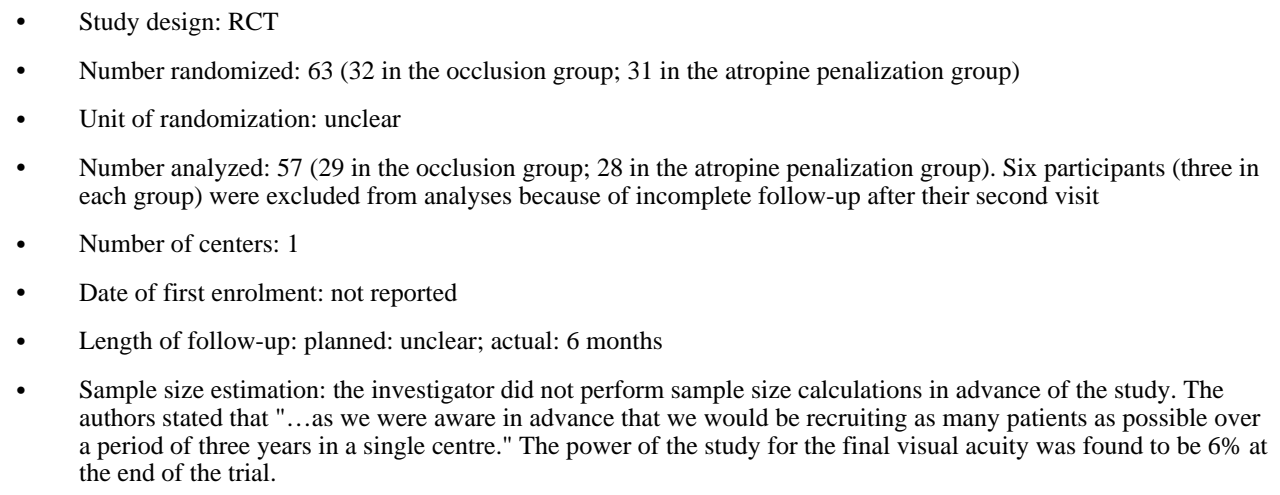 \\
\hline Participants & $\begin{array}{l}\text { - } \text { Country: India } \\
\text { - } \\
20 \text { years) } \\
\text { - } \quad \text { Sex: not reported } \\
\text { - } \quad \text { Key inclusion criteria: anisometropic hypermetropia of more than } 1 \text { diopter; inter eye visual acuity difference of } \geq \\
3 \text { logMAR lines; visual acuity in sound eye of }>6 / 9 \text {; visual acuity of amblyopic eye between } 6 / 12 \text { and } 6 / 60 \text {. } \\
\text { - } \quad \text { Key exclusion criteria: myopia; more than } 2 \text { months of amblyopia therapy in the past } 2 \text { years, and a known skin } \\
\text { reaction to patches or allergy to atropine. } \\
\text { - } \quad \text { Frequency of strabismus as the cause of amblyopia: } 0 \% \\
\text { - } \quad \text { Baseline visual acuity in the amblyopic eye: } 0.66 \text { logMAR in occlusion group, } 0.64 \text { logMAR in atropine } \\
\text { penalization group } \\
\text { - Comparability of baseline characteristics: comparable }\end{array}$ \\
\hline Interventions & $\begin{array}{l}\text { - Intervention regimen \#1: Full-time patching of the sound eye using Micropore tape (3M, St.Paul, MN) attached to } \\
\text { a piece of opaque oval paper. Patching was alternated between the sound eye and amblyopic eye with 6:1 ratio } \\
\text { (i.e.,patching of the sound eye for } 6 \text { days followed by patching of the amblyopic eye for } 1 \text { day). } \\
\text { Intervention regimen \#2: One drop per day of atropine sulphate } 1 \% \text {. Daily use continued until visual acuity } \\
\text { reached the desired level (not specified), or if there was no improvement in visual acuity for } 3 \text { months, at which } \\
\text { point a minimum twice weekly regimen was adopted. }\end{array}$ \\
\hline Outcomes & $\begin{array}{l}\text { - Primary outcome: not specified } \\
\text { - Outcomes reported: visual acuity measure using ETDRS and Snellen chart at } 6 \text { months of treatment, near vision, } \\
\text { contrast sensitivity, stereo acuity, and compliance }\end{array}$ \\
\hline Notes & $\begin{array}{ll}\text { - } & \text { Funding sources:none declared } \\
\text { - } & \text { Statistical analyses: P-values, rather than effect estimates and confidence intervals were reported } \\
\text { - } & \text { Subgroup analyses: performed }\end{array}$ \\
\hline \multicolumn{2}{|l|}{ PEDIG 2008} \\
\hline Methods & 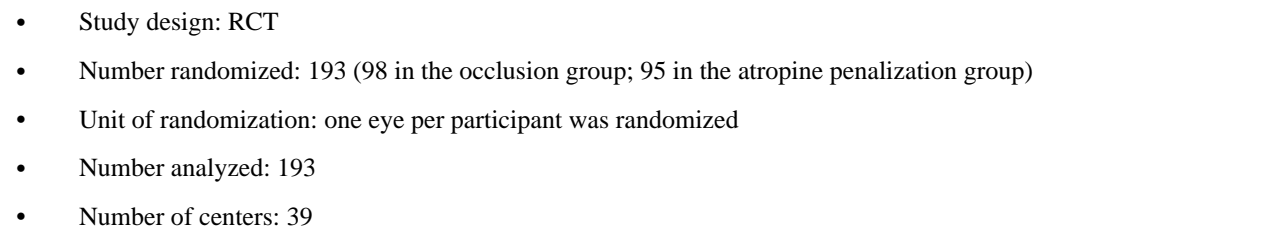 \\
\hline
\end{tabular}


- Date of first enrolment: August 1, 2005

- Length of follow-up: planned: 17 weeks; actual: 17 weeks.

- Sample size estimation: the trial was designed to evaluate whether patching and atropine are equivalent treatments for amblyopia in children aged 7 to 12 years. A sample size of 180 subjects had $90 \%$ power and a type I error rate of 5\% for an equivalence limit of 5 letters (1 line) based on the following assumptions: SD of 17-week visual acuity scores of 10 letters, correlation between outcome and baseline visual acuity scores of 0.30 , and $10 \%$ unavailable for follow-up.

\begin{tabular}{|c|c|c|}
\hline Participants & & 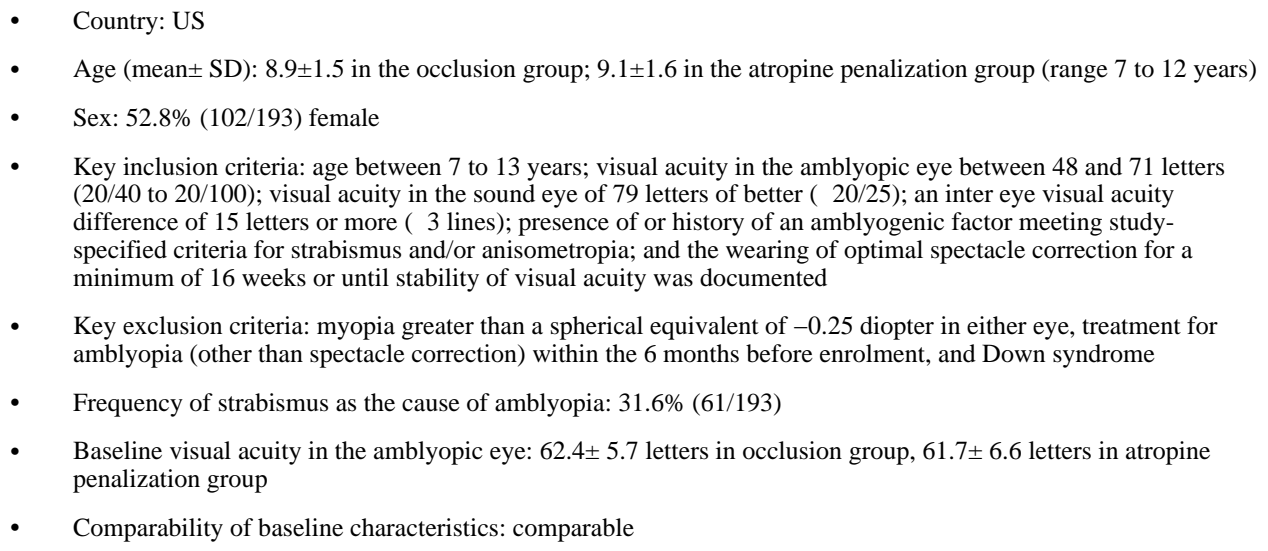 \\
\hline Interventions & & $\begin{array}{l}\text { - Intervention regimen \#1:occlusion was initially prescribed two hours of patching per day plus near visual tasks to } \\
\text { be done while wearing the patch for at least one hour per day. At the 5-week visit, if the amblyopic eye acuity had } \\
\text { not improved at least } 5 \text { letters from baseline, patching was increased. } \\
\text { Intervention regimen \#2: One drop of atropine sulphate } 1 \% \text { to be placed in the sound eye on Saturday and Sunday } \\
\text { of each week plus near visual tasks to be done at least one hour per day. If reading glasses have been prescribed, } \\
\text { near activities must be done without the use of reading glasses for at least an hour a day. If the amblyopic eye } \\
\text { acuity has not improved at least } 5 \text { letters from baseline to the 5-week visit, atropine will be increased to } 1 \text { drop in } \\
\text { the sound eye daily. }\end{array}$ \\
\hline Outcomes & & $\begin{array}{l}\text { - Primary outcome: visual acuity measured using E-ETDRS testing procedure at } 17 \text {-week visit. } \\
\text { - Secondary outcomes: } 1 \text { ) proportion of patients with } 17 \text {-week visual acuity in the amblyopic eye of } 20 / 25 \text { of better; } \\
\text { 2) proportion of patients with } 17 \text {-week visual acuity in the amblyopic eye improved } 15 \text { or more letters from } \\
\text { baseline; 3) stereo acuity at } 17 \text {-week; 4) amblyopia treatment index. }\end{array}$ \\
\hline Notes & & $\begin{array}{ll}\text { - } & \text { Funding sources:Grant EY011751, National Eye Institute, National Institute of Health, Bethesda, Maryland, USA } \\
\text { - } & \text { Statistical analyses: appropriate } \\
\text { - } & \text { Subgroup analyses: reported }\end{array}$ \\
\hline \multicolumn{3}{|l|}{ Yan 2008} \\
\hline Methods & NA & \\
\hline Participants & NA & \\
\hline Interventions & NA & \\
\hline Outcomes & NA & \\
\hline Notes & NA & \\
\hline
\end{tabular}

Footnotes

Full text unavailable. 